\title{
NO Oxidation Catalysis on Pt Clusters: Elementary Steps, Structural Requirements, and Synergistic Effects of $\mathrm{NO}_{2}$ Adsorption Sites
}

\author{
Brian M. Weiss and Enrique Iglesia* \\ Department of Chemical Engineering, University of California, and Chemical Sciences Division, \\ E. O. Lawrence Berkeley National Laboratory, Berkeley, California 94720
}

Received: March 12, 2009; Revised Manuscript Received: June 3, 2009

\begin{abstract}
Kinetic and isotopic methods show that $\mathrm{NO}$ oxidation on supported Pt clusters involves kinetically relevant reaction of $\mathrm{O}_{2}$ with vacancy sites on surfaces nearly saturated with oxygen adatoms $\left(\mathrm{O}^{*}\right)$. The oxygen chemical potential at Pt surfaces that determines the $\mathrm{O}^{*}$ coverage is rigorously described by an $\mathrm{O}_{2}$ virtual pressure and determined by the thermodynamics of $\mathrm{NO}_{2}-\mathrm{NO}$ interconversion reactions. $\mathrm{NO}$ oxidation and oxygen isotopic exchange processes are described by the same rate constant, consistent with similar kinetically relevant $\mathrm{O}_{2}$ dissociation steps for both reactions. $\mathrm{NO}$ oxidation, $\mathrm{NO}_{2}$ decomposition, and ${ }^{16} \mathrm{O}_{2}-{ }^{18} \mathrm{O}_{2}$ exchange rates increased markedly with increasing Pt cluster size $(1-8 \mathrm{~nm})$; these clusters remain metallic at all $\mathrm{O}_{2}$ virtual pressures prevalent during NO oxidation. These effects of cluster size reflect the higher vacancy concentrations and more facile oxygen desorption on larger Pt clusters, which bind oxygen adatoms weaker than more coordinatively unsaturated surface Pt atoms on smaller clusters. These trends are similar to those found for methane and dimethyl ether combustion on $\mathrm{Pt}$ and $\mathrm{Pd}$ catalysts, which also require vacancy sites on $\mathrm{O}_{\text {*- }}$ saturated cluster surfaces in their respective kinetically relevant steps. Inhibition of $\mathrm{NO}$ oxidation by $\mathrm{NO}_{2}$ persists to undetectable $\mathrm{NO}_{2}$ concentrations; thus, $\mathrm{NO}$ oxidation turnover rates increase significantly when $\mathrm{NO}_{2}$ adsorption sites present on $\mathrm{BaCO}_{3} / \mathrm{Al}_{2} \mathrm{O}_{3}$ are placed within diffusion distances of Pt clusters. $\mathrm{NO}$ oxidation rates on intrapellet catalyst-adsorbent mixtures are described accurately by a simple reaction-adsorption model in which $\mathrm{NO}_{2}$ adsorbs via displacement of $\mathrm{CO}_{2}$ on $\mathrm{BaCO}_{3}$ surfaces.
\end{abstract}

\section{Introduction}

$\mathrm{NO}_{x}$ storage systems consisting of noble metal catalysts and alkali or alkaline-earth adsorbents offer potential strategies to remove $\mathrm{NO}_{x}$ from fuel-lean combustion exhaust ${ }^{1}$ but require larger amounts of costly noble metals than alternate abatement strategies, thus hindering their widespread use., In these systems, noble metals catalyze $\mathrm{NO}$ oxidation to form $\mathrm{NO}_{2}$, which then binds onto adsorbents; ${ }^{1}$ the detailed mechanisms for oxidation and adsorption and for the coupling of these two functions remain controversial and incompletely understood. ${ }^{2}$

NO oxidation kinetics on $\mathrm{Pt} / \mathrm{Al}_{2} \mathrm{O}_{3}$ are consistent with kinetically relevant molecular $\mathrm{O}_{2}$ adsorption on $\mathrm{Pt}$ surfaces nearly saturated with chemisorbed oxygen $\left(\mathrm{O}^{*}\right) .{ }^{4}$ Density functional theory (DFT) treatments concluded that chemisorbed NO increases $\mathrm{O}_{2}$ dissociation rates and leads to higher $\mathrm{O}^{*}$ coverages than achieved by exposing catalysts to $\mathrm{O}_{2}$ in the absence of $\mathrm{NO}_{x}$ coreactants. ${ }^{5}$ Rate data on catalysts with varying $\mathrm{Pt}$ dispersion and cluster size indicate that NO oxidation occurs more rapidly on large than small Pt clusters. ${ }^{6}$ These studies, however, failed to show whether cluster size effects reflect the formation of inactive $\mathrm{Pt}$ oxides or stronger surface $\mathrm{Pt}-\mathrm{O}$ bonds for small clusters. ${ }^{6}$

The effects of $\mathrm{NO}_{2}$ adsorbents on $\mathrm{NO}$ oxidation processes have been examined by measuring NO conversion rates on catalyst-adsorbent mixtures. These studies have claimed that atomic contact among $\mathrm{Pt}$ and $\mathrm{BaO}$ species is required for efficient $\mathrm{NO}_{2}$ removal. ${ }^{7-9}$ These conclusions relied on data from materials for which the structure of Pt clusters and of $\mathrm{BaO}$

*Corresponding author. Fax: (510) 642-4778. E-mail: iglesia@ berkeley.edu. adsorption sites changed concurrently with their proximity. ${ }^{7-9}$ Detailed kinetic interpretations have also been rendered equivocal by the complete NO conversion levels that prevailed throughout these studies. ${ }^{7-9}$

Here, we provide kinetic and isotopic evidence for the identity and relevance of elementary steps involved in NO oxidation on Pt clusters under conditions of strict kinetic control. We show that oxygen isotopic exchange requires kinetically relevant steps identical to those involved in NO oxidation, confirming that these processes reflect the dynamics of $\mathrm{O}_{2}$ reaction with surface vacancies and the thermodynamics of oxygen binding. We also show that steady-state $\mathrm{O} *$ coverages during $\mathrm{NO}$ oxidation are lower than those that would exist in equilibrium with prevailing $\mathrm{O}_{2}$ pressures and that the observed effects of Pt cluster size on turnover rates reflect the stronger binding of chemisorbed oxygen on low-coordination surface atoms that prevail on small clusters. These effects of size on turnover rates reflect the requirement for vacancies within chemisorbed oxygen adlayers in kinetically relevant steps, as also shown for $\mathrm{CH}_{4}$ oxidation on $\mathrm{Pt}$ and $\mathrm{PdO}_{x}$ clusters ${ }^{10,11}$ and dimethyl either oxidation on $\mathrm{Pt}$ clusters. ${ }^{12}$ Finally, we have measured NO oxidation rates on mixtures of Pt catalysts and $\mathrm{BaCO}_{3}$ adsorbents to show that adsorbents increase $\mathrm{NO}$ oxidation rates by scavenging $\mathrm{NO}_{2}$ molecules that inhibit NO oxidation. The pervasive proximity requirements in catalyst-adsorbent formulations appear, for the most part, to result from $\mathrm{NO}_{2}$ inhibition of $\mathrm{NO}$ oxidation rates on $\mathrm{Pt}$, which persists even at the very low $\mathrm{NO}_{2}$ pressures $(<1$ $\mathrm{Pa}$ ) prevalent in catalyst-adsorbent systems, instead of an essential requirement for atomic connectivity between $\mathrm{Pt}$ and $\mathrm{BaO}$ sites. 


\section{Experimental Methods}

2.1. Catalyst Synthesis and Characterization of Pt Clusters. $\gamma-\mathrm{Al}_{2} \mathrm{O}_{3}$ (Sasol SBa-200, $150 \mathrm{~m}^{2} \mathrm{~g}^{-1}$ ) support powders were heated to $1023 \mathrm{~K}$ at $0.07 \mathrm{~K} \mathrm{~s}^{-1}$ in flowing dry air (Praxair, extra dry, $\left.1 \mathrm{~cm}^{3} \mathrm{~s}^{-1} \mathrm{~g}^{-1}\right)$ for $4 \mathrm{~h}$ before impregnation with precursor salts at ambient temperature. $\mathrm{Pt}\left(\mathrm{NH}_{3}\right)_{4}\left(\mathrm{NO}_{3}\right)_{2}$ (Alfa Aesar, $99.99 \%$ ) or $\mathrm{Ba}\left(\mathrm{CH}_{3} \mathrm{COO}\right)_{2}$ (Alfa Aesar, $99.999 \%$ ) was dissolved in deionized water to prepare catalysts with $1.2 \mathrm{wt} \%$ Pt content and adsorbents with 17 wt $\% \mathrm{BaCO}_{3}$. Solutions were added dropwise to $\mathrm{Al}_{2} \mathrm{O}_{3}(3-5 \mathrm{~g})$ up to the point of incipient wetness $\left(0.5 \mathrm{~cm}^{3} \mathrm{~g}^{-1}\right)$. Impregnated materials were treated in stagnant ambient air at $393 \mathrm{~K}$ for $4 \mathrm{~h} . \mathrm{Al}_{2} \mathrm{O}_{3}$ samples impregnated with $\mathrm{Pt}$ were heated in flowing dry air (Praxair, extra dry, $1 \mathrm{~cm}^{3} \mathrm{~s}^{-1} \mathrm{~g}^{-1}$ ) at $0.07 \mathrm{~K} \mathrm{~s}^{-1}$ to temperatures between 673 and $948 \mathrm{~K}$ and held at the final temperature for $4 \mathrm{~h}$; these procedures led to samples with a range of $\mathrm{Pt}$ fractional dispersions $(0.1-0.7)$ and cluster size $(1-8 \mathrm{~nm})$. Samples impregnated with $\mathrm{Ba}\left(\mathrm{CH}_{3} \mathrm{COO}\right)_{2}$ were heated to $723 \mathrm{~K}$ in flowing dry air (Praxair, extra dry, $1 \mathrm{~cm}^{3} \mathrm{~s}^{-1} \mathrm{~g}^{-1}$ ) at $0.07 \mathrm{~K}$ $\mathrm{s}^{-1}$, held at $723 \mathrm{~K}$ for $3 \mathrm{~h}$, cooled to ambient temperature, and treated in flowing $10 \% \mathrm{CO}_{2} / \mathrm{He}$ (Praxair, 99.999\%, $1 \mathrm{~cm}^{3} \mathrm{~s}^{-1}$ $\mathrm{g}^{-1}$ ) to form reproducible samples containing $\mathrm{BaCO}_{3}$, which would have otherwise formed upon intervening exposure to ambient air. ${ }^{13}$

The fraction of Pt atoms exposed at surfaces was measured from uptakes of irreversibly chemisorbed $\mathrm{H}_{2}$ at $313 \mathrm{~K}$ (Quantachrome analyzer). ${ }^{12}$ Average cluster sizes were estimated from Pt dispersion values by assuming hemispherical clusters with the metal density of bulk Pt $\left(21.45 \mathrm{~g} \mathrm{~cm}^{-3}\right) .{ }^{14} \mathrm{X}$-ray diffraction patterns were measured using a Siemens D5000 diffractometer, $\mathrm{Cu} \mathrm{K} \alpha$ radiation and a scan rate of $0.2^{\circ} \mathrm{min}^{-1}$. $\mathrm{PtO}_{2}(99.9 \%)$ was obtained from Sigma-Aldrich.

2.2. NO Oxidation Rate Measurements. Reactant gases (99.999\% purity) were obtained from Praxair (2\% NO/2\% Ar/ $\mathrm{He}, 1 \% \mathrm{NO}_{2} / \mathrm{He}, 10 \% \mathrm{O}_{2} / \mathrm{He}$ ) and metered using electronic controllers (Porter Instruments). He (Praxair, 99.999\%) was used as an inert carrier. $\mathrm{NO}_{2}$-containing mixtures were passed through $200 \mathrm{mg}$ of $\mathrm{Pt} / \mathrm{SiO}_{2}$ (0.36 dispersion, prepared in the same manner as $\mathrm{Pt} / \mathrm{Al}_{2} \mathrm{O}_{3}$; Davison grade 62 Silica Gel) kept at $323 \mathrm{~K}$ to remove impurities; such impurities have been claimed by others ${ }^{15}$ and caused significant deactivation unless removed in our case. Catalysts were pelleted and sieved to retain $0.18-0.25$ $\mathrm{mm}$ aggregates and held within a fritted quartz reactor $(10 \mathrm{~mm})$ kept at constant temperature by a resistively heated furnace. Temperatures were measured by K-type thermocouples at the outer reactor wall and controlled electronically (Watlow Series 96). Concentrations in the inlet and outlet streams were measured with a MKS Multigas 2030 infrared analyzer $\left(2 \mathrm{~cm}^{3}\right.$ cell; $2 \mathrm{~cm}$ path length, $338 \mathrm{~K}$ ). $\mathrm{NO}$ oxidation rates are reported here as turnover rates (per surface $\mathrm{Pt}$ atom, $\mathrm{Pt}_{\mathrm{s}}$ ) at $\mathrm{NO}$ conversions below $25 \%$. For conversions above $10 \%$, rates were determined by an integral reactor formalism that incorporated the measured rate equation and plug-flow hydrodynamics.

Rates were measured between 553 and $683 \mathrm{~K}$ for inlet streams containing $\mathrm{NO}(0.048-0.242 \mathrm{kPa}), \mathrm{O}_{2}(0.3-8 \mathrm{kPa})$, and $\mathrm{NO}_{2}$ $(0.002-0.129 \mathrm{kPa})$. Pt catalysts were treated at $673 \mathrm{~K}$ in flowing $2 \mathrm{kPa} \mathrm{H}_{2} / \mathrm{He}$ (Praxair, 99.999\% purity, $8 \mathrm{~cm}^{3} \mathrm{~s}^{-1} \mathrm{~g}^{-1}$ ) for $1 \mathrm{~h}$ before rate measurements. NO oxidation rates were also measured after catalysts were exposed to flowing $\mathrm{O}_{2}$ (Praxair, 99.999\% purity, $8 \mathrm{~cm}^{3} \mathrm{~s}^{-1} \mathrm{~g}^{-1}, 101 \mathrm{kPa}$ ) as noted in section 3.3 .

Catalyst-adsorbent mixtures were prepared by mixing $\mathrm{Pt} /$ $\mathrm{Al}_{2} \mathrm{O}_{3}$ and $\mathrm{BaCO}_{3} / \mathrm{Al}_{2} \mathrm{O}_{3}$ components $(0.005-0.05 \mathrm{~g}$ of catalyst $\left.(\mathrm{g} \text { of adsorbent })^{-1}\right)$ within the same pellets $(0.12-0.18 \mathrm{~mm}$ diameter) or as separate pellets $(0.12-0.43 \mathrm{~mm}$ diameter $)$. The size of the grains within pellets was $<0.04 \mathrm{~mm}$. Catalyst - adsorbent mixtures were heated to $573 \mathrm{~K}$ at $0.08 \mathrm{~K} \mathrm{~s}^{-1}$ in a flowing mixture containing $0.5 \mathrm{kPa} \mathrm{O}_{2}$ and $0.5 \mathrm{kPa} \mathrm{CO}_{2}\left(8 \mathrm{~cm}^{3} \mathrm{~s}^{-1} \mathrm{~g}^{-1}\right)$ and held for $1 \mathrm{~h}$ in flowing $0.5 \mathrm{kPa} \mathrm{O}_{2}$ before exposure to $\mathrm{NO}$ oxidation reactant mixtures. Adsorbent materials did not catalyze reactions of $\mathrm{NO}-\mathrm{O}_{2}$ in the absence of $\mathrm{Pt}$ catalysts. The cumulative $\mathrm{NO}_{x}$ adsorption on $\gamma-\mathrm{Al}_{2} \mathrm{O}_{3}\left(20 \mu \mathrm{mol} \mathrm{NO} \mathrm{g}^{-1}\right)$ was much less than on $\mathrm{BaCO}_{3} / \mathrm{Al}_{2} \mathrm{O}_{3}\left(170 \mu\right.$ mol $\left.\mathrm{NO}_{x} \mathrm{~g}^{-1}\right)$; thus, $\mathrm{NO}_{x}$ adsorption on $\mathrm{Pt} / \mathrm{Al}_{2} \mathrm{O}_{3}$ did not contribute significantly to the measured rate transients at the catalyst to adsorbent ratios used here. The dilution of $\mathrm{Pt} / \gamma-\mathrm{Al}_{2} \mathrm{O}_{3}$ catalysts with additional $\gamma-\mathrm{Al}_{2} \mathrm{O}_{3}$ within pellets or the dilution of catalyst-adsorbent mixtures with separate quartz particles within the bed (SigmaAldrich, acid washed and calcined, $1.25 \mathrm{~g}, 0.18-0.25 \mathrm{~mm}$ ) did not affect steady-state NO oxidation rates, confirming the absence of intrapellet or bed temperature gradients. ${ }^{16}$

2.3. Oxygen Isotopic Exchange Rate Measurements. ${ }^{16} \mathrm{O}_{2}-{ }^{18} \mathrm{O}_{2}$ exchange rates were measured on $\mathrm{Pt} / \mathrm{Al}_{2} \mathrm{O}_{3}$ in a gradientless recirculating batch reactor $\left(498 \mathrm{~cm}^{3}\right.$ volume, Agilent 5890 gas chromatograph, mass selective detection). ${ }^{17}$ Reactants and inert gases $(99.999 \%$ chemical purity) were obtained from Praxair ( $\mathrm{He}, \mathrm{H}_{2}, 90 \% \mathrm{O}_{2} / 10 \%$ Ar), Ikon Isotopes $\left(2 \%{ }^{18} \mathrm{O}_{2} / 2 \%\right.$ $\mathrm{Ar} / \mathrm{He}, 96 \%$ isotopic purity), and Sigma-Aldrich $\left({ }^{18} \mathrm{O}_{2}, 98 \%\right.$ isotopic purity). Catalysts were heated to $723 \mathrm{~K}$ at $0.1 \mathrm{~K} \mathrm{~s}^{-1}$, held for $1 \mathrm{~h}$ in $5 \mathrm{kPa} \mathrm{H} / \mathrm{He}\left(30 \mathrm{~cm}^{3} \mathrm{~s}^{-1} \mathrm{~g}^{-1}\right)$, and cooled to reaction temperatures $(613-693 \mathrm{~K})$ in flowing $\mathrm{He}\left(30 \mathrm{~cm}^{3} \mathrm{~s}^{-1}\right.$ $\left.\mathrm{g}^{-1}\right)$. A flow of $2 \mathrm{kPa} \mathrm{O}_{2} / \mathrm{He}\left(30 \mathrm{~cm}^{3} \mathrm{~s}^{-1} \mathrm{~g}^{-1}\right)$ was maintained for $1 \mathrm{~h}$ before each experiment to ensure $\mathrm{O}_{2}$ adsorption-desorption equilibrium. The batch reactor was filled with an equimolar mixture of ${ }^{18} \mathrm{O}_{2}-{ }^{16} \mathrm{O}_{2}$ at either 2 or $20 \mathrm{kPa}$ total $\mathrm{O}_{2}$ pressures; Ar was used as an internal standard and $\mathrm{He}$ as an inert to maintain ambient pressure. Exchange rates were determined from measured isotopic contents in dioxygen as a function of contact time, using methods described in the Supporting Information (section A.1) and previously proposed. ${ }^{18}$

The rates of ${ }^{18} \mathrm{O}_{2}(\mathrm{~g})$ exchange with chemisorbed ${ }^{16} \mathrm{O} *$ were measured in the flow reactor described in Section 2.2. $\mathrm{Pt} / \mathrm{Al}_{2} \mathrm{O}_{3}$ catalysts were heated in flowing $2 \mathrm{kPa} \mathrm{H}_{2}\left(4 \mathrm{~cm}^{3} \mathrm{~s}^{-1} \mathrm{~g}^{-1}\right)$ to $873 \mathrm{~K}$ at $0.08 \mathrm{~K} \mathrm{~s}^{-1}$ and held for $1 \mathrm{~h}$. Samples were cooled to $698 \mathrm{~K}$ in $\mathrm{He}\left(4 \mathrm{~cm}^{3} \mathrm{~s}^{-1} \mathrm{~g}^{-1}\right)$ and treated in $2 \mathrm{kPa}{ }^{16} \mathrm{O}_{2}\left(4 \mathrm{~cm}^{3}\right.$ $\left.\mathrm{s}^{-1} \mathrm{~g}^{-1}\right)$ for $1 \mathrm{~h}$, and then cooled to $373 \mathrm{~K}$. These samples were then exposed to $2 \mathrm{kPa}{ }^{18} \mathrm{O}_{2}$ and $2 \mathrm{kPa} \mathrm{Ar}\left(0.5 \mathrm{~cm}^{3} \mathrm{~s}^{-1} \mathrm{~g}^{-1}\right)$ and heated to $698 \mathrm{~K}$ at $0.17 \mathrm{~K} \mathrm{~s}^{-1}$, while the isotopic content of the effluent was determined by mass spectrometry (Transpector 2; Inficon) during this process.

\section{Results and Discussion}

3.1. Kinetics and Mechanistic Interpretation of NO Oxidation Pathways on Pt Clusters. Figure 1 shows the kinetic response of $\mathrm{NO}$ oxidation reactions to $\mathrm{NO}, \mathrm{NO}_{2}$, and $\mathrm{O}_{2}$ pressures on $\mathrm{Pt} / \mathrm{Al}_{2} \mathrm{O}_{3}$ (0.47 dispersion) at $573 \mathrm{~K}$. NO oxidation turnover rates are proportional to $\mathrm{NO}$ and $\mathrm{O}_{2}$ pressures and inversely proportional to $\mathrm{NO}_{2}$ throughout the range of reactant and product concentrations examined here. Measured NO oxidation rates are accurately described by the equation:

$$
r_{\mathrm{NO}}=k_{\mathrm{Pt}}[\mathrm{NO}]^{1}\left[\mathrm{O}_{2}\right]^{1}\left[\mathrm{NO}_{2}\right]^{-1}(1-\eta)
$$

consistent with previous data. ${ }^{4}$ Here, $\eta$ is the approach-toequilibrium factor, given by $K_{\mathrm{R}}{ }^{-1}\left[\mathrm{NO}_{2}\right]^{2}[\mathrm{NO}]^{-2}\left[\mathrm{O}_{2}\right]^{-1}$, and $K_{\mathrm{R}}$ is the equilibrium constant for the overall reaction: 


$$
2 \mathrm{NO}+\mathrm{O}_{2} \rightleftarrows 2 \mathrm{NO}_{2}
$$

The value of $K_{\mathrm{R}}$ was determined from thermodynamic data. ${ }^{14}$

We consider the sequence of elementary steps previously proposed for $\mathrm{NO}$ oxidation ${ }^{4,15}$ and depicted in Scheme 1. $\mathrm{O}_{2}$ adsorbs molecularly onto a vacant site (*; step 1) and dissociates via reaction with a vicinal site to form chemisorbed oxygen $\left(\mathrm{O}^{*}\right.$; step 2 ) or via reaction with chemisorbed $\mathrm{NO}$ to form adsorbed $\mathrm{NO}_{2}$ and $\mathrm{O}^{*}$ (step 2a). Vacancies form via reactions of $\mathrm{NO}$ with $\mathrm{O} *$ to form $\mathrm{NO}_{2}$ in quasi-equilibrated steps. Step 3 is not an elementary reaction as written, but instead reflects a sequence of quasi-equilibrated elementary steps that can be rigorously combined in the kinetic analysis. When $\mathrm{O}^{*}$ and * are the most abundant surface intermediates and $\mathrm{O}_{2} *$ species dissociate before they desorb, step 1 becomes the sole kinetically relevant step and NO oxidation rates are given by

$$
r_{\mathrm{NO}}=\frac{k_{1}\left[\mathrm{O}_{2}\right]}{1+K_{3}\left[\mathrm{NO}_{2}\right][\mathrm{NO}]^{-1}}(1-\eta)
$$

Here, $\eta$ has the same meaning as in eq 1 and represents the ratio of the forward to the reverse rate of NO oxidation, as derived from rigorous nonequilibrium thermodynamic treatments of chemical kinetics. ${ }^{19}$ Equation 3 becomes identical to the expression that accurately describes all rate data (eq 1) when chemisorbed $\mathrm{O}^{*}$ atoms are the most abundant adsorbed intermediates $\left(K_{3}\left[\mathrm{NO}_{2}\right][\mathrm{NO}]^{-1} \gg 1\right)$, an assumption that we use throughout the rest of this manuscript. As we discuss in section 3.3 , the ability of this equation to accurately describe NO oxidation rates indicates that the number and reactivity of active sites are unchanged throughout the entire range of oxygen chemical potential prevalent during catalysis.

3.2. Oxygen Isotopic Exchange and NO Oxidation Rates on $\mathbf{P t} / \mathrm{Al}_{2} \mathbf{O}_{3}$. The NO oxidation rate expression (eqs 1 and 3 ) is consistent with the reaction of $\mathrm{O}_{2}$ and an oxygen vacancy in the kinetically relevant step. Here, we probe $\mathrm{O}_{2}$ interactions with vacancies on surfaces nearly saturated with $\mathrm{O}^{*}$ by measuring rates of $\mathrm{NO}$ oxidation and ${ }^{16} \mathrm{O}_{2}-{ }^{18} \mathrm{O}_{2}$ exchange. These data and the preferential formation of mixed isotopomers during initial

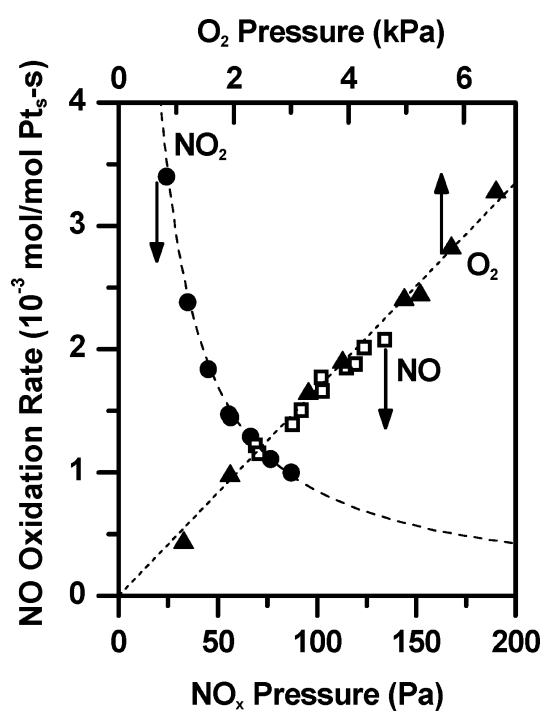

Figure 1. Effects of $\mathrm{NO}(\square), \mathrm{NO}_{2}(\bullet)$, and $\mathrm{O}_{2}(\boldsymbol{\Delta})$ pressures on forward $\mathrm{NO}$ oxidation rates on $\mathrm{Pt} / \mathrm{Al}_{2} \mathrm{O}_{3}(0.47$ dispersion $)$ at $573 \mathrm{~K}$. Each pressure was varied separately while others were kept at $5 \mathrm{kPa} \mathrm{O}_{2}, 56$ $\mathrm{Pa} \mathrm{NO}$, or $113 \mathrm{~Pa} \mathrm{NO}$.

\section{SCHEME 1: Proposed NO Oxidation Mechanism}

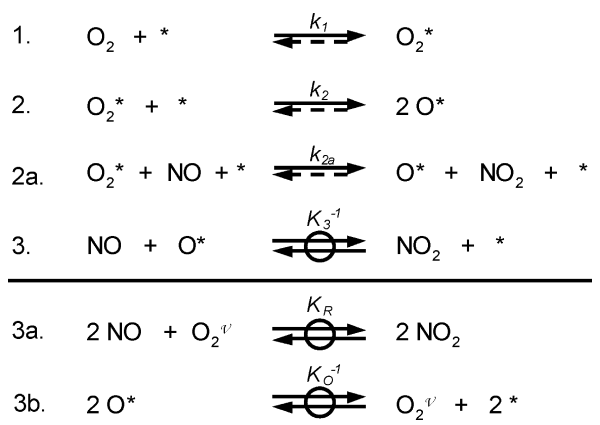

contact of ${ }^{18} \mathrm{O}_{2}$ with ${ }^{16} \mathrm{O}^{*}$ confirmed that $\mathrm{O}_{2}$ dissociation occurs without assistance from $\mathrm{NO}$ and involves mobile O-adatoms, which react with $\mathrm{O}^{*}$ to form $\mathrm{O}_{2}$ during exchange and with $\mathrm{NO}$ during its oxidation to form $\mathrm{NO}_{2}$.

${ }^{16} \mathrm{O}_{2}-{ }^{18} \mathrm{O}_{2}$ exchange (in the absence of $\mathrm{NO}$ ) occurs at $\mathrm{O}^{*}$ coverages in chemical equilibrium with prevalent dioxygen pressures. The oxygen chemical potentials that determine $\mathrm{O}^{*}$ coverages during $\mathrm{NO}$ oxidation, however, depend on $\mathrm{NO}_{2} / \mathrm{NO}$ ratios instead of $\mathrm{O}_{2}$ pressures. As a result, rigorous comparisons between isotopic exchange and $\mathrm{NO}$ oxidation rates require that we measure both reaction rates at the same oxygen chemical potential. We relate oxygen chemical potentials in both processes by noting that the quasi-equilibrated step that determines $\mathrm{O}^{*}$ coverages during NO oxidation (step 3 of Scheme 1) can be rigorously separated into two steps: the stoichiometric NO oxidation reaction (step 3a) and a quasi-equilibrated $\mathrm{O}_{2}$ dissociation step (step $3 b$ ). The latter reflects equilibration with a hypothetical or virtual $\mathrm{O}_{2}$ pressure, which represents the chemical potential of oxygen at surfaces during catalysis. Its value determines the coverage of chemisorbed $\mathrm{O}^{*}$ and the tendency of metal clusters to form bulk oxides. Chemisorbed $\mathrm{O} *$ coverages during $\mathrm{NO}$ oxidation catalysis are those that would be in equilibrium with this virtual oxygen pressure, $\mathrm{O}_{2}{ }^{v}$ (instead of $\mathrm{O}_{2}(\mathrm{~g})$ ), which is determined by the equilibration of $\mathrm{NO}_{2}(\mathrm{~g})$ and $\mathrm{NO}(\mathrm{g})$ with chemisorbed oxygen (in step 3). This virtual $\mathrm{O}_{2}$ pressure is given by:

$$
\mathrm{O}_{2}^{v}=\left[\mathrm{NO}_{2}\right]^{2}[\mathrm{NO}]^{-2} K_{\mathrm{R}}^{-1}
$$

where $K_{\mathrm{R}}$ is the equilibrium constant for eq 2 and is available from thermodynamic data for gas phase reactants and products. Therefore, oxygen coverages during NO oxidation catalysis are identical to those present during isotopic exchange only when the virtual $\mathrm{O}_{2}$ pressures during the former equal the actual $\mathrm{O}_{2}(\mathrm{~g})$ pressures used during isotopic exchange measurements. This treatment also shows that the equilibrium constant for step 3, $K_{3}$, is related to $K_{\mathrm{R}}$ and to the equilibrium constant for dissociative oxygen chemisorption, $K_{\mathrm{O}}$, by

$$
K_{3}=\left(K_{\mathrm{O}} / K_{\mathrm{R}}\right)^{1 / 2}
$$

Insertion of eqs 4 and 5 into eq 3 leads to NO oxidation rates that can be expressed solely in terms of the actual and virtual $\mathrm{O}_{2}$ pressures, the dynamics $\left(k_{1}\right)$ of molecular $\mathrm{O}_{2}$ reaction with vacancies, and the thermodynamics $\left(K_{\mathrm{O}}\right)$ for $\mathrm{O}_{2}$ dissociation on Pt clusters 


$$
\vec{r}_{\mathrm{NO}}=\frac{k_{1}\left[\mathrm{O}_{2}\right]}{K_{\mathrm{O}}{ }^{1 / 2}\left[\mathrm{O}_{2}{ }^{v}\right]^{1 / 2}}
$$

This equation shows that NO oxidation rates depend only on the dynamics and thermodynamics of oxygen adsorption and are independent of the binding properties of $\mathrm{NO}$ and $\mathrm{NO}_{2}$.

We compare next isotopic exchange rates measured at particular $\mathrm{O}_{2}(\mathrm{~g})$ pressures with $\mathrm{NO}$ oxidation rates measured at equivalent virtual $\mathrm{O}_{2}$ pressures (determined by $\mathrm{NO}_{2} / \mathrm{NO}$ ratios). Specifically, we compare reverse NO oxidation rates with isotopic oxygen exchange rates because both depend only on oxygen chemical potentials. Reverse rates of $\mathrm{NO}$ oxidation $\left(\mathrm{NO}_{2}\right.$ decomposition) are given by the product of the forward rate (eq 6) and the approach-to-equilibrium factor, $\eta$ (eq 4)

$$
\bar{r}_{\mathrm{NO}}=\frac{k_{1}}{K_{\mathrm{O}}{ }^{1 / 2}}\left[\mathrm{O}_{2}{ }^{{ }^{1 / 2}}\right.
$$

Reverse NO oxidation rates are also equal to $\mathrm{NO}_{2}$ decomposition rates for reactant mixtures with equivalent values of $\mathrm{O}_{2}{ }^{\nu}$; both rates reflect the molecular desorption of $\mathrm{O}_{2} *$ intermediates (the reverse of step 1 in Scheme 1). The mechanism for NO oxidation and its reverse includes a set of elementary steps that could occur during isotopic exchange (steps 1 and 2 of Scheme 1). If all of the kinetically relevant rate constants for $\mathrm{NO}$ oxidation and for isotopic exchange were equal, then reverse NO oxidation rates would be identical to isotopic exchange rates when reactant pressures are adjusted to achieve a standard oxygen chemical potential.

Figure 2a shows reverse $\mathrm{NO}$ oxidation rates at $2 \mathrm{kPa} \mathrm{O}_{2}{ }^{v}$ and ${ }^{16} \mathrm{O}_{2}-{ }^{18} \mathrm{O}_{2}$ exchange at $2 \mathrm{kPa} \mathrm{O}_{2}(\mathrm{~g})$ on $\mathrm{Pt} / \mathrm{Al}_{2} \mathrm{O}_{3}(0.47$ dispersion). Reverse NO oxidation rates were obtained from the product of $\eta$ and the forward NO oxidation rate measured at $7 \mathrm{kPa} \mathrm{O}_{2}(\mathrm{~g})$, and also from direct measurements of $\mathrm{NO}_{2}$ decomposition rates (without added $\mathrm{O}_{2}$ ). Measured $\mathrm{NO}_{2}$ decomposition rates were identical to those calculated for the reverse reaction from $\mathrm{NO}$ oxidation rates on $\mathrm{Pt} / \mathrm{Al}_{2} \mathrm{O}_{3}(0.47$ dispersion) at similar virtual $\mathrm{O}_{2}$ pressures, consistent with the accuracy of eqs 3 and 7 and of the defining equation for $\mathrm{O}_{2}$ virtual pressures (eq 4). These two rates were also identical to ${ }^{18} \mathrm{O}_{2}-{ }^{16} \mathrm{O}_{2}$ exchange rates at all temperatures, and similar activation energies were found for all of these processes (108 $\pm 16 \mathrm{~kJ} \mathrm{~mol}^{-1}$ for exchange; $120 \pm 10 \mathrm{~kJ} \mathrm{~mol}^{-1}$ for $\mathrm{NO}_{2}$ decomposition; $116 \pm 8 \mathrm{~kJ} \mathrm{~mol}^{-1}$ for reverse NO oxidation; $613-693 \mathrm{~K}$ ), suggesting that both processes have similar kinetic parameters. Isotopic $\mathrm{O}_{2}$ exchange rates on $\mathrm{Pt}$ films are proportional to $\left[\mathrm{O}_{2}\right]^{1 / 2}$, ${ }^{20}$ similar to the dependence of reverse NO oxidation rates on the oxygen chemical potential (eq 7). Isotopic exchange rates on $\mathrm{Pt} / \mathrm{Al}_{2} \mathrm{O}_{3}(0.47$ dispersion $)$ were $7 \times 10^{-3}$ and $3 \times 10^{-2} \mathrm{~mol} / \mathrm{mol} \mathrm{Pt}_{\mathrm{s}} \mathrm{s}$ at 2 and $20 \mathrm{kPa} \mathrm{O}_{2}$, respectively, also consistent with the $\left.\left[\mathrm{O}_{2}\right]\right]^{1 / 2}$ dependence. ${ }^{16} \mathrm{O}_{2}-{ }^{18} \mathrm{O}_{2}$ exchange rates per surface $\mathrm{Pt}$ atom increased sharply as $\mathrm{Pt}$ dispersion increased (Figure $2 \mathrm{~b}$ ). The turnover rates for isotopic exchange reported here on small clusters $(2-8 \mathrm{~nm})$ are lower (by factors of 3-23 times at $673 \mathrm{~K}$ ) than rates on Pt films (extrapolated to $673 \mathrm{~K}$ from $523 \mathrm{~K}$ ). ${ }^{20}$ These effects of cluster size are similar to those reported here (Figure 3) and in a previous study ${ }^{6}$ for $\mathrm{NO}$ oxidation and $\mathrm{NO}_{2}$ decomposition on Pt clusters.

The similar rates and (virtual) $\left[\mathrm{O}_{2}\right]^{1 / 2}$ dependences for $\mathrm{NO}_{2}$ decomposition and ${ }^{16} \mathrm{O}_{2}-{ }^{18} \mathrm{O}_{2}$ exchange indicate that $\mathrm{O}_{2}{ }^{*}$ desorption from $\mathrm{Pt}$ surfaces is kinetically relevant in both processes and that $\mathrm{O}^{*}$ coverages are in equilibrium with $\mathrm{O}_{2}{ }^{v}$
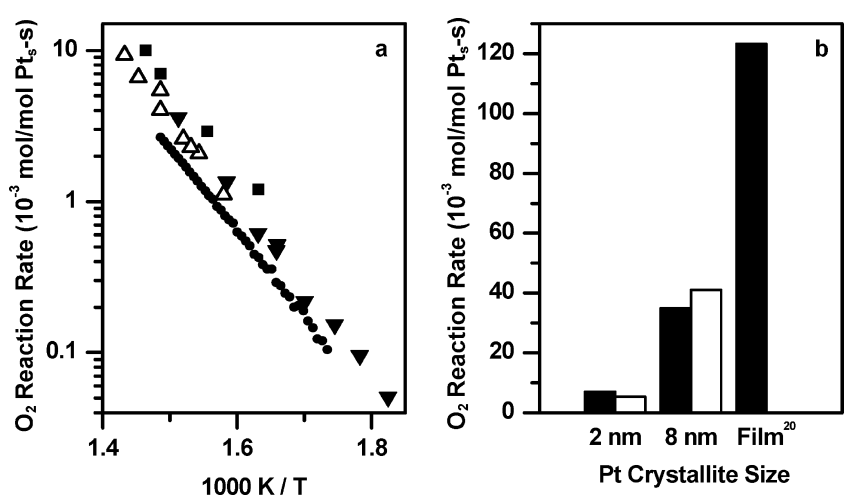

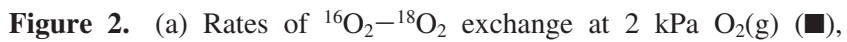
${ }^{18} \mathrm{O}_{2}-{ }^{16} \mathrm{O} *$ exchange at $2 \mathrm{kPa} \mathrm{O}_{2}(\mathrm{~g})(\bullet), \mathrm{NO}_{2}$ decomposition at $2 \mathrm{kPa}$ $\mathrm{O}_{2}{ }^{\mathrm{V}}(\triangle)$, and reverse $\mathrm{NO}$ oxidation at $2 \mathrm{kPa} \mathrm{O}_{2}{ }^{v}$ and $7 \mathrm{kPa} \mathrm{O}(\mathrm{g})(\boldsymbol{\nabla})$ on $\mathrm{Pt} / \mathrm{Al}_{2} \mathrm{O}_{3}$ with 0.47 dispersion. (b) ${ }^{16} \mathrm{O}_{2}-{ }^{18} \mathrm{O}_{2}$ exchange at $2 \mathrm{kPa}$ $\mathrm{O}_{2}(\mathrm{~g})$ (black) and reverse NO oxidation rates at $2 \mathrm{kPa} \mathrm{O}_{2}{ }^{\mathrm{V}}$ (white) on $\mathrm{Pt} / \mathrm{Al}_{2} \mathrm{O}_{3}$ at $673 \mathrm{~K}$. The results for Pt film are extrapolated from ref 20 and assume $10^{15} \mathrm{Pt}_{\mathrm{s}} \mathrm{cm}^{-2}$.

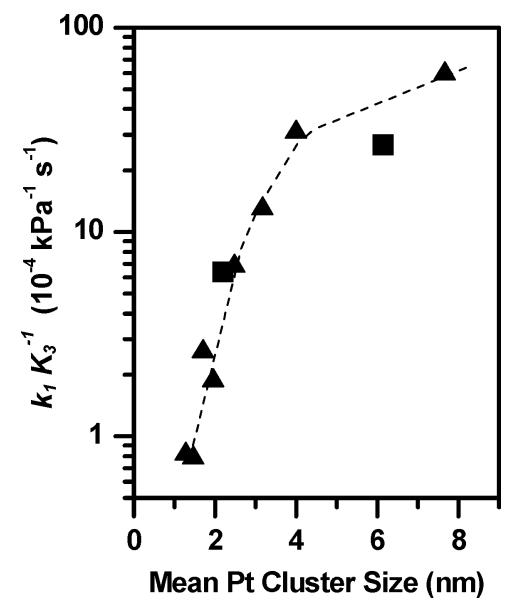

Figure 3. NO oxidation rate constants, $k_{1} K_{3}{ }^{-1}$, as a function of mean cluster size on $\mathrm{Pt} / \mathrm{Al}_{2} \mathrm{O}_{3}$ at $603 \mathrm{~K}$ for $\mathrm{NO}$ oxidation measured at 0.15 $\mathrm{kPa} \mathrm{O}_{2}, 5 \mathrm{kPa} \mathrm{O} \mathrm{O}_{2}(\mathbf{\Delta})$ and from ref $6(\mathbf{\square})$.

during catalysis and with $\mathrm{O}_{2}(\mathrm{~g})$ during exchange. The reaction of $\mathrm{O}_{2}$ with a vacancy proceeds at the same rate as $\mathrm{O}_{2} *$ desorption (its microscopic reverse) during isotopic exchange, which occurs at chemical equilibrium. These results and the pseudosteady state hypothesis (PSSH) on reaction intermediates lead to a rate expression for isotopic exchange, which we describe briefly here and in more detail in section A.1 of the Supporting Information. Application of PSSH to each $\mathrm{O}_{2} *$ intermediate leads to

$$
\begin{gathered}
\frac{\left[{ }^{16} \mathrm{O}_{2}^{*}\right]}{\left[\mathrm{O}_{2}{ }^{*}\right]}=\left(\frac{\left[{ }^{16} \mathrm{O}^{*}\right]}{\left[\mathrm{O}^{*}\right]}\right)^{2} \\
\frac{\left[{ }^{18} \mathrm{O}_{2}^{*}\right]}{\left[\mathrm{O}_{2}{ }^{*}\right]}=\left(\frac{\left[{ }^{18} \mathrm{O}^{*}\right]}{\left[\mathrm{O}^{*}\right]}\right)^{2} \\
\frac{\left[{ }^{16} \mathrm{O}^{18} \mathrm{O}^{*}\right]}{\left[\mathrm{O}_{2}{ }^{*}\right]}=2 \frac{\left[{ }^{16} \mathrm{O}^{*}\right]\left[{ }^{18} \mathrm{O}^{*}\right]}{\left[\mathrm{O}^{*}\right]^{2}}
\end{gathered}
$$

These equations show that the isotopic fractions of $\mathrm{O}_{2}{ }^{*}$ species adopt a binomial distribution that depends on the fraction of ${ }^{16} \mathrm{O}^{*}$ and ${ }^{18} \mathrm{O}^{*}$ on the surface. Application of PSSH to $\mathrm{O}^{*}$ 
species leads to an expression for their isotopic fraction in terms of gas phases concentrations

$$
\begin{aligned}
& \frac{\left[{ }^{16} \mathrm{O}^{*}\right]}{\left[\mathrm{O}^{*}\right]}=\frac{\left[{ }^{16} \mathrm{O}_{2}+{ }^{16} \mathrm{O}^{18} \mathrm{O} / 2\right]}{\left[\mathrm{O}_{2}\right]} \\
& \frac{\left[{ }^{18} \mathrm{O} *\right]}{\left[\mathrm{O}^{*}\right]}=\frac{\left[{ }^{18} \mathrm{O}_{2}+{ }^{16} \mathrm{O}^{18} \mathrm{O} / 2\right]}{\left[\mathrm{O}_{2}\right]}
\end{aligned}
$$

The exchange rate, $r_{\text {exch }}$, is obtained by combining eqs $8-12$ with the rate of any elementary adsorption step, leading to

$$
r_{\mathrm{exch}}=\frac{k_{1}}{K_{\mathrm{O}}{ }^{1 / 2}}\left[\mathrm{O}_{2}\right]^{1 / 2}\left(\frac{\left[{ }^{16} \mathrm{O}_{2}\right]\left[{ }^{18} \mathrm{O}_{2}\right]}{\left[\mathrm{O}_{2}\right]^{2}}-\frac{\left[{ }^{16} \mathrm{O}^{18} \mathrm{O}^{2} / 4\right.}{\left[\mathrm{O}_{2}\right]^{2}}\right)
$$

This equation shows that isotopic exchange involves the same rate constants as forward and reverse NO oxidation (eqs 6 and 7) and the same $\left[\mathrm{O}_{2}\right]^{1 / 2}$ dependence as $\mathrm{NO}_{2}$ decomposition (eq 7). The exchange rate also includes a factor (in the parentheses of eq 13) that we have already accounted in Figure 2, which is independent of the kinetically relevant exchange steps ${ }^{18}$ and corrects for the changing isotopic fractions in the gas phase.

As shown by eqs 6 and 13, the kinetically relevant steps of NO oxidation and isotopic exchange involve the reaction of molecular $\mathrm{O}_{2}$ with *. We investigate next whether the subsequent $\mathrm{O}_{2} *$ dissociation steps require two vacancies (according to step 2 of Scheme 1) by considering the interaction of ${ }^{18} \mathrm{O}_{2}(\mathrm{~g})$ with surfaces nearly saturated by ${ }^{16} \mathrm{O}^{*}$. This process differs from ${ }^{16} \mathrm{O}_{2}-{ }^{18} \mathrm{O}_{2}$ exchange because the isotopic fractions of $\mathrm{O}^{*}$ species depend on rates of elementary steps, as opposed to gas phase concentrations (eqs 11-12, which are valid when PSSH applies). Thus, the exchange pathway that involves $\mathrm{O}_{2}$ dissociation on two vacancies and $\mathrm{O}^{*}$ recombination (step 2 in Scheme 1) leads to the initial formation of only ${ }^{16} \mathrm{O}_{2}$ during ${ }^{18} \mathrm{O}_{2^{-}}{ }^{16} \mathrm{O}^{*}$ exchange (additional details given in section A.1 of the Supporting Information). The measured ${ }^{18} \mathrm{O}_{2}(\mathrm{~g})$ consumption rate (at $2 \mathrm{kPa}{ }^{18} \mathrm{O}_{2}$ ) during ${ }^{18} \mathrm{O}_{2}-{ }^{16} \mathrm{O} *$ exchange was similar to reverse NO oxidation and ${ }^{16} \mathrm{O}_{2}{ }^{18} \mathrm{O}_{2}$ exchange rates (Figure $2 \mathrm{a}$ ), confirming that $\mathrm{O}_{2}$ dissociation occurs by the same kinetically relevant step in all cases. The initial ${ }^{18} \mathrm{O}_{2}-{ }^{16} \mathrm{O} *$ exchange product was mainly ${ }^{16} \mathrm{O}^{18} \mathrm{O}$, which formed more than twice as fast as ${ }^{16} \mathrm{O}_{2}$ (exchange rates versus temperature, 573-683 K, reported in section A.1 of the Supporting Information). The predominant formation of ${ }^{16} \mathrm{O}^{18} \mathrm{O}$ during initial contact of ${ }^{18} \mathrm{O}_{2}$ with ${ }^{16} \mathrm{O}^{*}$ surfaces is consistent with exchange (and $\mathrm{O}_{2}$ dissociation) that occurs via the formation of a mobile oxygen atom from $\mathrm{O}_{2}$ *, which reacts mainly with chemisorbed $\mathrm{O} *$ (to give ${ }^{16} \mathrm{O}^{18} \mathrm{O}$ during ${ }^{18} \mathrm{O}_{2}-{ }^{16} \mathrm{O} *$ exchange) and to a lesser extent with vacancies (to give ${ }^{16} \mathrm{O}_{2}$ ). The involvement of fast mobile oxygen species on $\mathrm{O}^{*}$-covered surfaces, detected here from isotopic exchange rates and selectivities, has been previously proposed to account for the effects of $\mathrm{O}_{2}$ pressure on the rates of $\mathrm{NO}$ decomposition. ${ }^{21}$ We conclude that $\mathrm{O}_{2}$ activation on $\mathrm{O}^{*}$-covered surfaces is limited by the reaction of $\mathrm{O}_{2}$ with a vacancy to form $\mathrm{O}^{*}$ and mobile oxygen adatoms that rapidly migrate among strongly bound $\mathrm{O} *$ species. These data and conclusions suggest that the cleavage of $\mathrm{O}=\mathrm{O}$ bonds occurs rapidly even without the assistance of coadsorbed reactants (e.g., $\mathrm{NO}^{*}$ or $\mathrm{CO}^{*}$, as proposed elsewhere ${ }^{15,22}$ ). Neither $\mathrm{O}_{2} *$ reactions with $\mathrm{NO} *$ (step 2a) nor their microscopic reverse are required in $\mathrm{NO} / \mathrm{NO}_{2}$
TABLE 1: Pre-Exponential Factors, $A$, and Apparent Activation Energies, $E_{1}+Q_{\mathrm{O}} / 2$, for $k_{1} K_{\mathrm{O}}{ }^{-1 / 2}$ on $\mathrm{Pt} / \mathrm{Al}_{2} \mathrm{O}_{3}$

\begin{tabular}{ccc}
\hline mean cluster size $(\mathrm{nm})$ & $A\left(10^{8} \mathrm{~s}^{-1}\right)$ & $E_{1}+Q_{\mathrm{O}} / 2\left(\mathrm{~kJ} \mathrm{~mol}^{-1}\right)$ \\
\hline 8 & $4 \pm 3$ & $121 \pm 5$ \\
2 & $1 \pm 0.9$ & $125 \pm 4$ \\
1 & $1 \pm 0.6$ & $129 \pm 4$
\end{tabular}

interconversions because direct dissociation involving mobile $\mathrm{O}$ species proceeds at much higher rates than these alternate pathways.

3.3. Effects of Pt Cluster Size on NO Oxidation and $\mathbf{O}_{2}$ Exchange Rates. The effects of Pt cluster size on NO oxidation rate constants $\left(k_{1} K_{3}^{-1}\right)$ are shown in Figure 3. NO oxidation rate constants increased monotonically with increasing cluster size ${ }^{6}$ concurrently with increases in isotopic oxygen exchange and $\mathrm{NO}_{2}$ decomposition rates (Figure 2b). Surface vacancies required in kinetically relevant steps for $\mathrm{NO}$ oxidation become increasingly scarce as the binding energy of chemisorbed oxygen atoms increases. $\mathrm{NO}_{2}$ decomposition and exchange rates also decrease with increasing $\mathrm{O}^{*}$ binding energy, because these reactions involve desorption of $\mathrm{O}_{2} *$ (via the microscopic reverse of the $\mathrm{O}_{2}$ dissociation pathways discussed previously), which becomes slower with increasing oxygen binding energy. Coverage-averaged heats of dissociative $\mathrm{O}_{2}$ adsorption $\left(Q_{\mathrm{O}}\right)$ decrease from $270 \mathrm{~kJ} \mathrm{~mol} \mathrm{O}_{2}^{-1}$ on Pt clusters $(2.5 \mathrm{~nm})$ to $220 \mathrm{~kJ}$ mol $\mathrm{O}_{2}{ }^{-1}$ on larger crystallites prevalent on Pt powders $(1600 \mathrm{~nm}),{ }^{23}$ suggesting that the cluster size effects are related to the oxygen binding energy through the $K_{\mathrm{O}}$ term in the rate constant (eq 6). Density functional theory calculations ${ }^{24}$ have shown that $\mathrm{O}^{*}$ binding energies decrease with cluster size because surface atoms in small clusters have higher degrees of coordinative unsaturation than surface Pt atoms in larger clusters; these trends are consistent with the observed effects of Pt cluster size on NO oxidation turnover rates.

Oxygen binding energies influence apparent NO oxidation rate constants through the effects of the $K_{O}$ term in the denominator of the rate equation (eq 6), which depends, in turn, on the heat of adsorption of $\mathrm{O}^{*}\left(Q_{\mathrm{O}} / 2\right)$ (defined as the negative of the adsorption enthalpy)

$$
\frac{k_{1}}{K_{\mathrm{O}}^{1 / 2}}=A \exp \left(-\frac{E_{1}+Q_{\mathrm{O}} / 2}{k_{\mathrm{B}} T}\right)
$$

Here, $E_{1}$ is the activation barrier for $\mathrm{O}_{2}$ reaction with $*$ and $A$ is the pre-exponential factor given by

$$
A=\frac{k_{\mathrm{B}} T}{h} \exp \left(\frac{\Delta S_{1}^{+}-\Delta S_{\mathrm{o}} / 2}{k_{\mathrm{B}}}\right)
$$

The activation entropy reflects the difference between the activation entropy for step 1 of Scheme $1\left(\Delta S_{\dot{1}}^{\dot{亠}}\right)$ and the entropy for the dissociative $\mathrm{O}_{2}$ chemisorption reaction to form $\mathrm{O} *\left(\Delta S_{\mathrm{O}} /\right.$ 2; step $3 \mathrm{~b}$ of Scheme 1). Measured pre-exponential factors and apparent activation energies are shown in Table 1 on $\mathrm{Pt} / \mathrm{Al}_{2} \mathrm{O}_{3}$ catalysts with $0.12,0.47$, and $0.72 \mathrm{Pt}$ dispersions. These preexponential factors give apparent activation entropies of -90 $\pm 6 \mathrm{~J} \mathrm{~mol}^{-1} \mathrm{~K}^{-1}$, consistent with immobile transition states and immobile chemisorbed $\mathrm{O}^{*}$ species (based on a standard entropy of $205 \mathrm{~J} \mathrm{~mol}^{-1} \mathrm{~K}^{-1}$ for $\left.\mathrm{O}_{2}(\mathrm{~g})^{14}\right)$. For small values of $E_{1}$, the measured NO oxidation activation energies correspond to dissociative heats of adsorption (at near saturation coverages) 
and increase from 240 to $260 \mathrm{~kJ}\left(\mathrm{~mol} \mathrm{O}_{2}\right)^{-1}$ as Pt cluster diameters increase from 1 to $8 \mathrm{~nm}$. These values are similar to heats of dissociative $\mathrm{O}_{2}$ adsorption on Pt clusters $(270 \mathrm{~kJ}$ (mol $\left.\mathrm{O}_{2}\right)^{-1}$ on $2.5 \mathrm{~nm} \mathrm{Pt}$ clusters ${ }^{23}$ ). Heats of $\mathrm{O} *$ adsorption on $\mathrm{Pt}$ single crystals decrease from $300 \mathrm{~kJ}\left(\mathrm{~mol} \mathrm{O}_{2}\right)^{-1}$ at low coverages on $\mathrm{Pt}(111)$ and $\mathrm{Pt}(110)$ facets to $140 \mathrm{~kJ}\left(\mathrm{~mol} \mathrm{O}_{2}\right)^{-1}$ and $220 \mathrm{~kJ}$ $\left(\mathrm{mol} \mathrm{O}_{2}\right)^{-1}$, respectively, at 0.30 coverages. ${ }^{25,26}$ Average heats of adsorption tend to overestimate the binding energy of the most weakly adsorbed oxygen adatoms, which desorb to form vacancies on saturated surfaces. Yet, these average values (270 $\mathrm{kJ}\left(\mathrm{mol} \mathrm{O}_{2}\right)^{-1}$ on $2.5 \mathrm{~nm} \mathrm{Pt}$ clusters $^{23}$ ) are only slightly larger than those inferred here $\left(Q_{\mathrm{O}}=240-260 \mathrm{~kJ}\left(\mathrm{~mol} \mathrm{O}_{2}\right)^{-1}\right)$ from $\mathrm{NO}$ oxidation activation energies and the assumption of nonactivated $\mathrm{O}_{2}$ adsorption $\left(E_{1}=0\right) . \mathrm{O}_{2}$ activation barriers estimated from DFT on $\mathrm{Pt}(111)$ nearly saturated by $\mathrm{CO}$ have been reported to be as high as $35 \mathrm{~kJ} \mathrm{~mol}^{-1}$, as a result of Coulombic repulsion among coadsorbed species. ${ }^{27}$ Such effects are likely to be even stronger on $\mathrm{O}^{*}$-saturated surfaces and to lead to significant activation barriers for $\mathrm{O}_{2}$ activation. Non-negligible activation barriers for $\mathrm{O}_{2}$ reaction with $*, E_{1}$, would decrease the heat of adsorption, $Q_{\mathrm{O}}$, required to describe measured NO oxidation activation energies. An increase in $E_{1}$ as $\mathrm{O}^{*}$ binding decreases with cluster size would be expected from ubiquitous linear free energy relations and may explain why the variation in measured NO oxidation activation energies with cluster size $\left(10 \mathrm{~kJ} \mathrm{~mol}^{-1}\right.$ for $1-8 \mathrm{~nm}$ clusters) is smaller than expected from the concomitant change in the heat of dissociative $\mathrm{O}_{2}$ chemisorption $\left(50 \mathrm{~kJ}\left(\mathrm{~mol} \mathrm{O}_{2}\right)^{-1}\right.$ for 3-1000 nm crystallites $\left.{ }^{23}\right)$.

Cluster size effects similar to those reported here for NO oxidation are also evident for the combustion of $\mathrm{CH}_{4}{ }^{10,11}$ and dimethyl ether ${ }^{12}$ on $\mathrm{PdO}_{x}$ and $\mathrm{Pt}$ clusters. These reactions also require vacancies on $\mathrm{O}^{*}$-saturated surfaces in their respective kinetically relevant steps, the activation of $\mathrm{C}-\mathrm{H}$ bonds on $*-\mathrm{O} *$ site pairs, in which $\mathrm{C}$-atoms interact with a vacancy and $\mathrm{H}$-atoms with $\mathrm{O}^{*}$. We conclude that these strong effects of cluster size are general features of reactions requiring vacancies on $\mathrm{O}^{*}$ saturated surfaces. In contrast, $\mathrm{CO}$ oxidation turnover rates, also limited by molecular adsorption of $\mathrm{O}_{2}$, but on $\mathrm{CO}^{*}$-covered surfaces, are independent of $\mathrm{Pt}$ or $\mathrm{Pd}$ cluster size (1.5-10 $\mathrm{nm}){ }^{28,29}$ Apparently, the size effects on binding energy are less pronounced for $\mathrm{CO}$, which prefers atop sites, ${ }^{30}$ than for $\mathrm{O}^{*}$, which prefers multicoordinate sites ${ }^{24}$ whose binding properties more strongly depend on surface structure.

We also consider that cluster size effects on NO oxidation turnover rates may arise from preferential formation of less reactive bulk oxides for smaller Pt clusters. Metal-oxygen bonds on metal cluster surfaces weaken as oxygen coverages increase $\mathrm{e}^{25,26}$ because of Coulombic repulsion between adsorbates. ${ }^{5}$ Such effects persist and become stronger as oxygen atoms start to bind with Pt atoms within clusters at higher oxygen chemical potentials. Thus, the formation of bulk oxides, per se, seems unlikely to make surfaces unreactive by decreasing vacancy concentrations during $\mathrm{NO}$ oxidation. Indeed, $\mathrm{CH}_{4}$ combustion turnover rates are much lower on $\mathrm{Pd}$ than on $\mathrm{PdO}$ clusters of similar size, because of the weaker surface $\mathrm{Pd}-\mathrm{O}$ bonds on the latter, which leads to higher concentrations of the vacancies required for $\mathrm{C}-\mathrm{H}$ bond activation. ${ }^{11}$

The remarkable accuracy with which the rate equations reported here and in a previous study ${ }^{4,6}$ (eqs 3,6) describe all NO oxidation rate data on large and small clusters over a $10^{3}$ fold range in $\mathrm{O}_{2}$ virtual pressures and $\mathrm{a} \sim 100 \mathrm{~K}$ range in temperatures indicates that either the phase of Pt clusters did not change within this range of oxygen chemical potentials or that such changes were catalytically inconsequential (Figure 4).

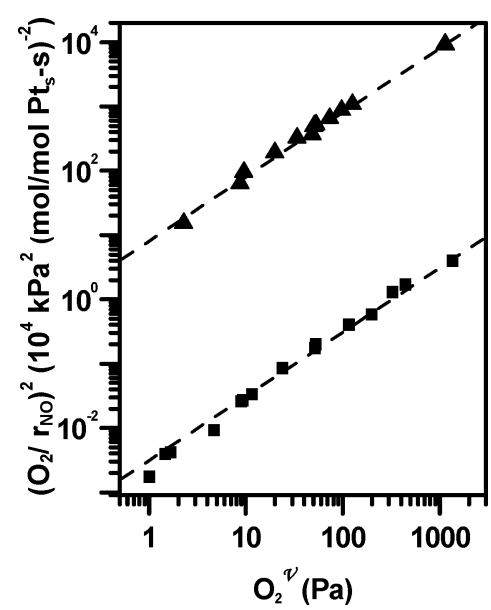

Figure 4. $\mathrm{NO}$ oxidation kinetic response to $\mathrm{O}_{2}{ }^{v}$ on $\mathrm{Pt} / \mathrm{Al}_{2} \mathrm{O}_{3}$ with 0.13

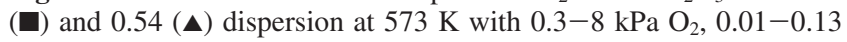
$\mathrm{kPa} \mathrm{NO}_{2}, 0.05-0.24 \mathrm{kPa} \mathrm{NO}$. The dashed lines model the data with eq 6 and have slopes equal to $K_{\mathrm{O}} k_{1}^{-2}$.

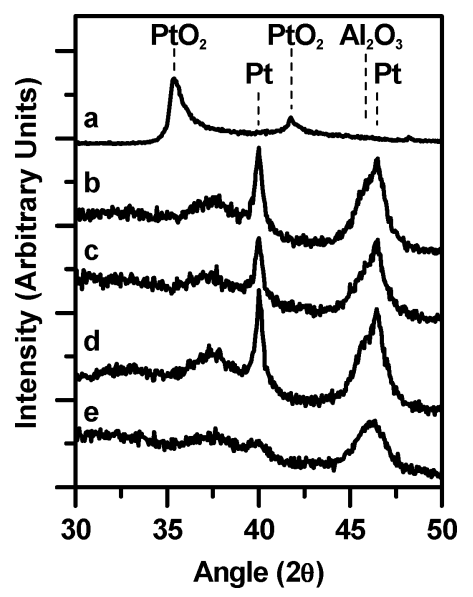

Figure 5. X-ray diffractograms of (a) $\mathrm{PtO}_{2}$ (standard), (b) $\mathrm{Pt} / \mathrm{Al}_{2} \mathrm{O}_{3}$ (0.13 dispersion) treated with $101 \mathrm{kPa} \mathrm{O}{ }_{2}(698 \mathrm{~K}, 12 \mathrm{~h})$, (c) $\mathrm{Pt} / \mathrm{Al}_{2} \mathrm{O}_{3}$ (0.13 dispersion) after $101 \mathrm{kPa} \mathrm{O}_{2}(633 \mathrm{~K}, 12 \mathrm{~h})$, (d) $\mathrm{Pt} / \mathrm{Al}_{2} \mathrm{O}_{3}(0.13$ dispersion) after $2 \mathrm{kPa} \mathrm{H}_{2}(673 \mathrm{~K}, 1 \mathrm{~h})$, and (e) $\mathrm{Pt}_{2} / \mathrm{Al}_{2} \mathrm{O}_{3}$ (0.5 dispersion) after $2 \mathrm{kPa} \mathrm{H}_{2}(673 \mathrm{~K}, 1 \mathrm{~h})$. Diffractograms collected in ambient conditions.

Specifically, eq 6 requires that $\left(\mathrm{O}_{2} / \vec{r}_{\mathrm{NO}}\right)^{2}$ be strictly proportional to $\mathrm{O}_{2}{ }^{v}$ with a slope equal to $K_{\mathrm{O}} k_{1}{ }^{-2}$. The data in Figure 4 show that this is indeed true throughout a $10^{3}$-fold range in oxygen virtual pressures $\left(\mathrm{O}_{2}{ }^{v}=0.001-1 \mathrm{kPa}\right)$ on both large and small clusters. Thus, neither small nor large clusters undergo any phase change consequential to surface reactivity for any subset of clusters within the respective size distributions in these catalysts; large clusters show higher turnover rates for all values of the prevalent oxygen chemical potential. Every cluster within the size distribution of these samples must therefore remain in either metal or oxide form throughout a $10^{3}$-fold change in prevalent oxygen chemical potentials.

We use thermodynamic data to assess the Pt phase that is present during $\mathrm{NO}$ oxidation. The enthalpy of $\mathrm{PtO}_{x}$ formation $\left(-66 \pm 20 \mathrm{~kJ}(\mathrm{~mol} \mathrm{O})^{-1}\right)^{31,32}$ and the reported $\mathrm{Pt}-\mathrm{PtO}_{x}$ phase diagrams (for bulk Pt; 2-400 $\mathrm{MPa} \mathrm{O}$, 873-1173 K) ) $^{33}$ extrapolated to NO oxidation conditions suggest that large $\mathrm{Pt}$ clusters should remain as the metal phase for all $\mathrm{O}_{2}{ }^{v}$ pressures below $1 \mathrm{kPa}$ at $573 \mathrm{~K}$. X-ray diffraction (Figure 5) confirmed that $8 \mathrm{~nm}$ Pt clusters are indeed metallic after treatment in $\mathrm{H}_{2}$ $(2 \mathrm{kPa}, 473 \mathrm{~K}, 1 \mathrm{~h})$ or $\mathrm{O}_{2}(101 \mathrm{kPa}, 603$ or $698 \mathrm{~K}, 12 \mathrm{~h})$; the latter $\mathrm{O}_{2}(\mathrm{~g})$ pressures are much larger than the $\mathrm{O}_{2}{ }^{v}$ values 


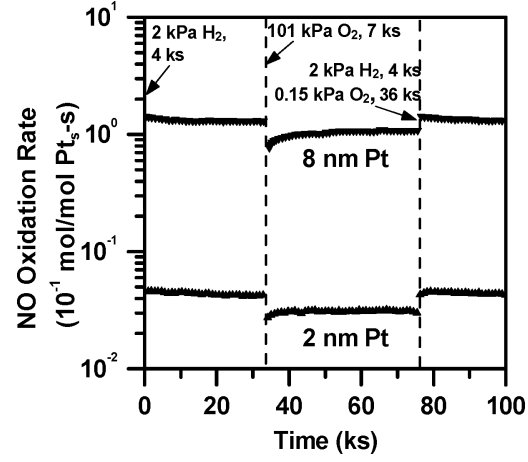

Figure 6. $\mathrm{NO}$ oxidation rates on $\mathrm{Pt} / \mathrm{Al}_{2} \mathrm{O}_{3}$ with 0.13 and 0.54 dispersion as a function of time-on-stream at $603 \mathrm{~K}, 0.15 \mathrm{kPa} \mathrm{O}_{2}{ }^{v}, 5 \mathrm{kPa} \mathrm{O}$. Vertical dashed lines represent treatments at the listed conditions.

prevalent during NO oxidation catalysis $(0.001-2 \mathrm{kPa}$; 553-673 K). Small Pt clusters (2 nm) did not show detectable diffraction lines before or after catalytic reactions, but their rates were also accurately described by eq 6 at all $\mathrm{O}_{2}{ }^{v}$ pressures. Thus, these Pt clusters are also metallic at all conditions; otherwise, higher $\mathrm{O}_{2}{ }^{v}$ pressures would progressively oxidize an increasing fraction of the smaller clusters present within their size distribution and preferentially retain larger clusters as metals. These trends would cause significant deviations from the linear dependence of $\left(\mathrm{O}_{2} /\right.$ $\left.\vec{r}_{\mathrm{NO}}\right)^{2}$ on oxygen virtual pressure (Figure 4 ) if the Pt phase changed with cluster size for a given oxygen chemical potential and the oxidation state of $\mathrm{Pt}$ atoms within clusters were consequential for oxygen binding and catalytic reactivity. The conclusion that $2 \mathrm{~nm}$ clusters in $\mathrm{Pt} / \mathrm{Al}_{2} \mathrm{O}_{3}(0.5$ dispersion $)$ are metallic during $\mathrm{NO}$ oxidation $\left(<2 \mathrm{kPa} \mathrm{O}_{2}{ }^{v} ; 553-673 \mathrm{~K}\right)$ is consistent with oxygen uptake measurements showing that only surface oxidation of $\mathrm{Pt} / \mathrm{Al}_{2} \mathrm{O}_{3}$ (0.56 dispersion) occurs at these conditions $\left(101 \mathrm{kPa} \mathrm{O}_{2} ; 300-900 \mathrm{~K}\right){ }^{34}$

The electronic and binding differences between small and large clusters are predominantly associated with the properties of their surfaces and cause smaller clusters to interact more strongly with adsorbed species. Adsorbed species decrease surface energies more effectively for small clusters because of their stronger binding, which reduces any incentive for small clusters to form bulk oxides at lower oxygen chemical potentials than larger clusters. We also expect that any effects of size on bulk oxidation tendency, inferred from surface energy and $\mathrm{M}-\mathrm{O}$ binding energy considerations, would be modest, because of the similar coordination of bulk atoms within large and small clusters and because of the weak effects $\left(<1 \mathrm{~kJ} \mathrm{~mol}^{-1}\right)^{5}$ of atoms beyond nearest and next-nearest neighbor positions on binding properties. The effects of coordination environment on surface energies appear to be much stronger than any effects of curvature enforced by size alone, ${ }^{24,35}$ suggesting that the effects of size on bulk oxidation are much more modest than previously claimed. ${ }^{36}$

The conclusion that the strong effects of cluster size on NO oxidation turnovers do not reflect preferential bulk oxidation of small clusters is consistent with NO oxidation turnover rates measured after thermal treatments intended to reduce or oxidize Pt clusters (Figure 6). $\mathrm{NO}$ oxidation rates on $\mathrm{Pt} / \mathrm{Al}_{2} \mathrm{O}_{3}$ catalysts with 0.13 and 0.54 dispersion treated in $\mathrm{H}_{2}$ before reaction (2 $\mathrm{kPa} ; 673 \mathrm{~K}, 1 \mathrm{~h})$ decreased only slightly $(<5 \%)$ during subsequent NO oxidation for $30 \mathrm{ks}$. Initial NO oxidation rates were smaller (by a factor of $\sim 2 ; 0.13$ dispersion) when treated in $\mathrm{O}_{2}\left(101 \mathrm{kPa} \mathrm{O}_{2}, 603 \mathrm{~K}, 2 \mathrm{~h}\right)$ instead of $\mathrm{H}_{2}$ before reaction, but rates increased gradually with time and reached values only $\sim 20 \%$ smaller than on samples pretreated in $\mathrm{H}_{2}$. These slight

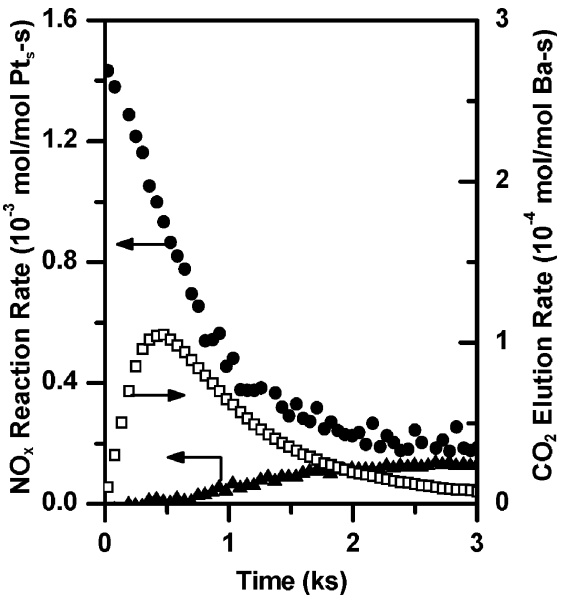

Figure 7. $\mathrm{NO}$ oxidation $(\bullet)$ and $\mathrm{NO}_{2}(\mathbf{\Delta})$ and $\mathrm{CO}_{2}(\square)$ elution rates after exposure of $0.5 \mathrm{kPa} \mathrm{O}, 0.178 \mathrm{kPa} \mathrm{NO}$ to $\mathrm{Pt} / \mathrm{Al}_{2} \mathrm{O}_{3}(1.4 \mathrm{mg}, 0.2$ dispersion) mixed within pellets of $\mathrm{BaCO}_{3} / \mathrm{Al}_{2} \mathrm{O}_{3}(125 \mathrm{mg})$ at $573 \mathrm{~K}$.

effects of thermal treatment and reaction time were even weaker on smaller Pt clusters (0.54 dispersion). NO oxidation rates have similar values after $\mathrm{H}_{2}$ treatments $\left(2 \mathrm{kPa} \mathrm{H}_{2}, 673 \mathrm{~K}, 1 \mathrm{~h}\right)$ and after $\mathrm{O}_{2}$ treatments at pressures corresponding to the $\mathrm{O}_{2}{ }^{v}$ values prevalent during $\mathrm{NO}$ oxidation $\left(0.15 \mathrm{kPa} \mathrm{O}_{2} ; 603 \mathrm{~K}, 12 \mathrm{~h}\right)$, suggesting that $\mathrm{Pt}$ surface structures are unaffected at lower oxygen chemical potentials. Large clusters gave higher turnover rates than small clusters after all treatments and at all reaction times. These data show that clusters less active for NO oxidation bind oxygen more strongly, thus disfavoring the formation of vacancies, but do not form bulk oxides; such oxides would, in any case, lead to weaker metal-oxygen bonds than in chemisorbed layers and to more reactive cluster surfaces. The weaker binding of oxygen on bulk oxides (relative to oxygen chemisorbed on metals) may also account for the high reactivity reported for $\mathrm{Co}_{3} \mathrm{O}_{4}$ catalysts in $\mathrm{NO}$ oxidation ${ }^{37}$ and oxygen isotopic exchange ${ }^{20}$ reactions.

3.4. NO Oxidation Turnover Rates on Mixtures of Pt/ $\mathbf{A l}_{2} \mathbf{O}_{3}$ and $\mathrm{NO}_{2}$ Adsorbents. The mechanism in Scheme 1 and its associated rate equation (eq 3) indicate that $\mathrm{NO}_{2}$ inhibits $\mathrm{NO}$ oxidation at any $\mathrm{NO}_{2} / \mathrm{NO}$ ratio that causes $\mathrm{Pt}$ surfaces to remain nearly saturated with $\mathrm{O} *$ via $\mathrm{NO}-\mathrm{NO}_{2}$ equilibration; such conditions persist throughout the accessible range of experimental $\mathrm{O}_{2}{ }^{v}$ pressures $(0.001-2 \mathrm{kPa})$ and detectable $\mathrm{NO}_{2}$ pressures $(>1 \mathrm{~Pa})$. In this section, we explore the catalytic consequences of depleting $\mathrm{NO}_{2}$ around $\mathrm{NO}$ oxidation sites on Pt clusters via $\mathrm{NO}_{2}$ adsorption onto nearby binding sites.

Figure 7 shows $\mathrm{NO}$ oxidation and $\mathrm{NO}_{2}$ evolution rates (per surface $\mathrm{Pt}$ atom) as a function of time on $\mathrm{Pt} / \mathrm{Al}_{2} \mathrm{O}_{3}$ catalysts (0.2 dispersion; $1.4 \mathrm{mg}$ ) present as intrapellet mixtures with $\mathrm{BaCO}_{3} / \mathrm{Al}_{2} \mathrm{O}_{3}$ adsorbents $(125 \mathrm{mg})$. NO oxidation rates decreased with time from 1.5 to $0.15 \mathrm{~mol} \mathrm{NO} / \mathrm{mol} \mathrm{Pt}_{\mathrm{s}}$-s at steadystate $(>2 \mathrm{ks})$. The $\mathrm{NO}_{2}$ concentration in the effluent increased with time as the number of adsorption sites decreased due to the displacement of $\mathrm{CO}_{2}$ with $\mathrm{NO}_{2} ; \mathrm{CO}_{2}$ evolution rates (per $\mathrm{Ba}$ atom) concurrently decreased (Figure 7). $\mathrm{NO}_{2}$ evolution and $\mathrm{NO}$ consumption rates became similar only after $\mathrm{NO}_{2}$ binding sites reached saturation. The $\mathrm{NO}_{2}$ evolution rate reflects the difference between $\mathrm{NO}$ oxidation, $r_{\mathrm{NO}}$, and $\mathrm{NO}_{2}$ adsorption, $r_{\mathrm{Ba}}$, rates per surface site 


$$
v \frac{\mathrm{d}\left[\mathrm{NO}_{2}\right]}{\mathrm{d} z}=\hat{L}_{\mathrm{Pt}}\left\langle r_{\mathrm{NO}}\right\rangle-\hat{L}_{\mathrm{Ba}}\left\langle r_{\mathrm{Ba}}\right\rangle
$$

Here, $z$ is the axial distance along the reactor, $v$ is the superficial gas velocity, and $\hat{L}_{\mathrm{Pt}}$ and $\hat{L}_{\mathrm{Ba}}$ represent the number of Pt surface atoms and of $\mathrm{NO}_{2}$ binding sites per unit volume, and $\hat{L}_{\mathrm{Ba}}$ decreases with time as adsorption sites saturate. Rates are defined at their local averages (bracket notation) because their actual values may differ from those expected at the concentration of various species in the extrapellet fluids because of intrapellet concentration gradients. Mean distances between $\mathrm{NO}$ oxidation and $\mathrm{NO}_{2}$ adsorption sites, $\mathrm{NO}_{2}$ diffusivities within the connecting pore structure, and $\mathrm{NO}_{2}$ adsorption rates determine local $\mathrm{NO}_{2}$ concentrations in catalyst and adsorbent mixtures (present within the same pellet or as separate pellets). Separate pellets of catalysts and adsorbents led to initial NO oxidation rates that increased by only a factor of $\sim 1.5$ as mean pellet diameters decreased from $0.34 \mathrm{~mm}$ to $0.15 \mathrm{~mm}$ (Table 2). Mixing the two components within the same pellet increased NO oxidation rates by only $\sim 1.3$ times compared with separate pellets of similar size $(0.12-0.18 \mathrm{~mm})$. Intrapellet mixtures contained grains $<0.04 \mathrm{~mm}$ in diameter; the $>10$-fold decrease in the distance between sites relative to separate pellets had a weak effect on NO oxidation rates. These weak effects of site proximity and their interpretation as evidence of kinetic control are consistent with estimates of the Mears parameter: ${ }^{38}$

$$
\Omega=\frac{\hat{r}_{\mathrm{NO}}}{D_{\mathrm{NO}_{2}}\left[\mathrm{NO}_{2}\right] L^{-2}}
$$

Small $\Omega$ values $(<1)$ would indicate negligible intrapellet gradients. These values are near unity $(1-2)$ for separate pellets (0.13-0.42 mm diameter), but much smaller for intrapellet mixtures (0.1, for $0.04 \mathrm{~mm}$ grains; Table 2) (details in Supporting Information; section A.2). These data are consistent with the absence of $\mathrm{NO}_{2}$ concentration gradients within intrapellet mixtures; thus, we remove the brackets in eq 16 and use kinetic rate equations for $\mathrm{NO}$ oxidation and $\mathrm{NO}_{2}$ adsorption steps

$$
v \frac{\mathrm{d}\left[\mathrm{NO}_{2}\right]}{\mathrm{d} z}=\hat{L}_{\mathrm{Pt}} r_{\mathrm{NO}}-\hat{L}_{\mathrm{Ba}} r_{\mathrm{Ba}}
$$

The rate of $\mathrm{NO}_{2}$ elution from the reactor, $r_{\mathrm{NO}_{2}}$, is given by integration of eq 18 throughout the reactor length. $\mathrm{NO}_{2}$ evolution rates were much smaller than $\mathrm{NO}$ oxidation rates $\left(r_{\mathrm{NO}} / r_{\mathrm{NO}_{2}}>\right.$ 10) during initial contact of these mixtures with $\mathrm{NO} / \mathrm{O}_{2}$ reactants $(<0.8 \mathrm{ks})$. Thus, $\mathrm{NO}$ oxidation and $\mathrm{NO}_{2}$ adsorption rates are much larger than their difference, and $\mathrm{NO}_{2}$ can be treated as a reactive intermediate present at its pseudosteady-state concentration $\left(\mathrm{d}\left[\mathrm{NO}_{2}\right] / \mathrm{d} t \sim 0\right)$ :

$$
\chi k_{\mathrm{Pt}} \frac{[\mathrm{NO}]\left[\mathrm{O}_{2}\right]}{\left[\mathrm{NO}_{2}\right]}=r_{\mathrm{Ba}}
$$

where $\chi$ is the ratio of the number of Pt surface atoms to $\mathrm{NO}_{2}$ adsorption sites

$$
\chi=L_{\mathrm{Pt}} / L_{\mathrm{Ba}}
$$

TABLE 2: Effect of Physical Proximity on NO Oxidation Rates in Catalyst-Adsorbent Mixtures

\begin{tabular}{cccc}
\hline $\begin{array}{c}\text { catalyst pellet } \\
\text { diameter }(\mathrm{mm})\end{array}$ & $\begin{array}{c}\text { initial NO } \\
\text { oxidation rate } \\
\left(\mathrm{mol} / \mathrm{mol} \mathrm{Pt}_{\mathrm{s}} \mathrm{s}\right)^{a}\end{array}$ & $\begin{array}{c}\text { initial } \mathrm{NO}_{2} \\
\text { pressure }(\mathrm{Pa})\end{array}$ & $\hat{r}_{\mathrm{NO}} / D\left[\mathrm{NO}_{2}\right] \mathrm{L}^{-2}$ \\
\hline $\begin{array}{c}\text { mixed within } \\
\text { adsorbent pellets }\end{array}$ & 1.3 & 0.8 & $0.1^{b}$ \\
$0.13-0.18$ & 1.0 & 1.0 & \\
$0.18-0.25$ & 0.8 & 1.2 & 1.1 \\
$0.25-0.42$ & 0.7 & 1.5 & 2.3
\end{tabular}

${ }^{a}$ Rates measured at $0.5 \mathrm{kPa} \mathrm{O}, 0.17 \mathrm{kPa} \mathrm{NO}, 573 \mathrm{~K}$ over mixtures containing $6 \mathrm{mg} \mathrm{Pt} / \mathrm{Al}_{2} \mathrm{O}_{3}$ (0.2 dispersion) and $125 \mathrm{mg}$ $\mathrm{BaCO}_{3} / \mathrm{Al}_{2} \mathrm{O}_{3} .{ }^{b} \mathrm{~L}$ estimated from the size of the largest grains, 0.04 $\mathrm{mm}$.

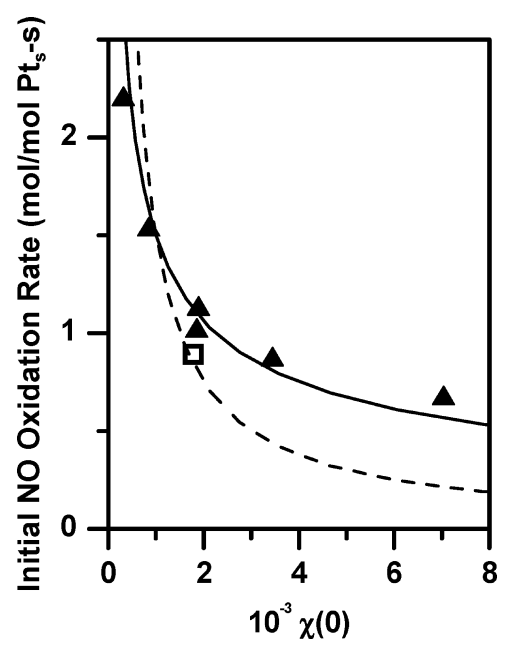

Figure 8. $\mathrm{NO}$ oxidation rates at $573 \mathrm{~K}, 0.5 \mathrm{kPa} \mathrm{O}, 0.178 \mathrm{kPa} \mathrm{NO}$ without $\mathrm{CO}_{2}$ in the inlet stream $(\mathbf{\Delta})$ and with $0.5 \mathrm{kPa} \mathrm{CO}(\square)$ over $\mathrm{Pt} / \mathrm{Al}_{2} \mathrm{O}_{3}\left(0.2\right.$ dispersion) mixed within pellets of $\mathrm{BaCO}_{3} / \mathrm{Al}_{2} \mathrm{O}_{3}$ as a function of catalyst to adsorbent ratio, $\chi(0)$. The solid and dashed lines show the $\chi$ dependence of eqs 26 and 27 , respectively.

and increases with time as adsorption sites saturate. $L_{\mathrm{Ba}}$ is given by the cumulative $\mathrm{NO}_{2}$ uptakes up to saturation coverages $(0.24$ \pm 0.02 per $\mathrm{Ba}$ atom for the sample and conditions here). Equation 19 indicates that the intrinsic adsorption rate, $r_{\mathrm{Ba}}$, and its dependence on reactant $\left(\mathrm{NO}, \mathrm{O}_{2}\right)$ or product $\left(\mathrm{NO}_{2}, \mathrm{CO}_{2}\right)$ concentrations and on the surface coverages of $\mathrm{NO}_{2}$ and $\mathrm{CO}_{2}$ determine prevalent $\mathrm{NO}_{2}$ concentrations and thus $\mathrm{NO}$ oxidation rates in these catalyst-adsorbent systems.

Next, we explore the effects of initial $\chi$ values, $\chi(0)$, on $\mathrm{NO}$ oxidation rates to probe the kinetics and mechanism of $\mathrm{NO}_{2}$ adsorption. Figure 8 shows $\mathrm{NO}$ oxidation rates as a function of $\chi(0)$, varied by the ratio of catalyst to adsorbent within intrapellet mixtures. Initial NO oxidation rates decreased with increasing $\chi(0)$, consistent with the higher local $\mathrm{NO}_{2}$ concentrations that prevail as the number of $\mathrm{NO}_{2}$ adsorption sites decreases relative to the number of Pt sites that form $\mathrm{NO}_{2} \cdot \mathrm{CO}_{2}$ pressures and elution rates varied with time (Figure 7), but the addition of $\mathrm{CO}_{2}(0.5 \mathrm{kPa})$ to $\mathrm{NO}-\mathrm{O}_{2}$ reactants even at pressures $(0.5 \mathrm{kPa})$ higher than those present for $\mathrm{CO}_{2}$-free reactants $(<0.01 \mathrm{kPa})$ decreased $\mathrm{NO}$ oxidation rates by less than $20 \%$ (Figure 8 ). These data indicate that the replacement of the adsorbed $\mathrm{CO}_{2}$ initially present on adsorption sites by $\mathrm{NO}_{2}$ occurs via irreversible steps.

We consider these effects of $\chi(0)$ and of $\mathrm{CO}_{2}$ on $\mathrm{NO}$ oxidation rates in the context of a rate equation and mechanism for $\mathrm{NO}_{2}$ adsorption and of the known rate equation for $\mathrm{NO}$ oxidation on Pt sites (eq 3). The replacement of chemisorbed $\mathrm{CO}_{2}$ by $\mathrm{NO}_{2}$ can occur via either concerted reactions (Scheme 2, step 1) or 
sequential $\mathrm{CO}_{2}$ desorption and $\mathrm{NO}_{2}$ adsorption onto the vacant site (Scheme 2, steps 1a and 1b). The respective adsorption rates for these two pathways are given by

$$
\begin{gathered}
r_{\mathrm{Ba}}=k_{1}^{\mathrm{Ba}}\left[\mathrm{NO}_{2}\right] \quad(\text { step } 1) \\
r_{\mathrm{Ba}}=\frac{k_{1 \mathrm{~b}}^{\mathrm{Ba}} k_{1 \mathrm{a}}^{\mathrm{Ba}}\left[\mathrm{NO}_{2}\right]}{k_{-1 \mathrm{a}}^{\mathrm{Ba}}\left[\mathrm{CO}_{2}\right]+k_{1 \mathrm{~b}}^{\mathrm{Ba}}\left[\mathrm{NO}_{2}\right]} \quad(\text { steps } 1 \mathrm{a} \text { and } 1 \mathrm{~b})
\end{gathered}
$$

The weak effects of high $\mathrm{CO}_{2}$ pressures $(0.5 \mathrm{kPa})$ on rates indicate that $\mathrm{CO}_{2}$ desorption is irreversible $\left(k_{-1 \mathrm{a}}^{\mathrm{Ba}}\left[\mathrm{CO}_{2}\right] \ll\right.$ $k_{1 \mathrm{~b}}^{\mathrm{Ba}}\left[\mathrm{NO}_{2}\right]$ ), because $\mathrm{CO}_{2}$ would otherwise inhibit $\mathrm{NO}_{2}$ adsorption (eq 22), leading to higher local $\mathrm{NO}_{2}$ concentrations (eq 19) and lower NO oxidation rates. Thus, eq 22 becomes

$$
r_{\mathrm{Ba}}=k_{1 \mathrm{a}}^{\mathrm{Ba}}
$$

Concerted (eq 23) and sequential (eq 21) $\mathrm{CO}_{2}$ displacement routes lead to different $\mathrm{NO}_{2}$ adsorption rate equations, which when inserted into the $\mathrm{NO}_{2}$ mole balance (eq 19) give local $\mathrm{NO}_{2}$ concentrations

$$
\begin{gathered}
{\left[\mathrm{NO}_{2}\right]=\left(\chi \frac{k_{\mathrm{Pt}}}{k_{1}^{\mathrm{Ba}}}[\mathrm{NO}]\left[\mathrm{O}_{2}\right]\right)^{1 / 2}} \\
{\left[\mathrm{NO}_{2}\right]=\chi \frac{k_{\mathrm{Pt}}}{k_{1 \mathrm{a}}^{\mathrm{Ba}}}[\mathrm{NO}]\left[\mathrm{O}_{2}\right]}
\end{gathered}
$$

for concerted and sequential $\mathrm{NO}_{2}$ adsorption routes, respectively. The use of these expressions for $\mathrm{NO}_{2}$ in eq 1 gives $\mathrm{NO}$ oxidation turnover rates in terms of $\chi(0)$

$$
\begin{gathered}
r_{\mathrm{NO}}=\left(\frac{k_{\mathrm{Pt}} k_{1}^{\mathrm{Ba}}[\mathrm{NO}]\left[\mathrm{O}_{2}\right]}{\chi(0)}\right)^{1 / 2} \\
r_{\mathrm{NO}}=\frac{k_{1 \mathrm{a}}^{\mathrm{Ba}}}{\chi(0)}
\end{gathered}
$$

for concerted and sequential routes, respectively.

These rate equations were integrated assuming 20\% NO conversion and plug-flow hydrodynamics, and their respective forms are shown in Figure 8 (solid and dashed lines for eqs 26 and 27 , respectively) together with $\mathrm{NO}$ oxidation rate data. Concerted routes (eq 26; Scheme 2, step 1) provide a more

\section{SCHEME 2: Elementary Steps of $\mathrm{NO}_{2}$ Adsorption}

$\begin{array}{llll}\text { 1. } & \mathrm{BaO}-\mathrm{CO}_{2}+\mathrm{NO}_{2} & \stackrel{k_{1}^{\mathrm{Ba}} \longrightarrow}{\longrightarrow} & \mathrm{BaO}-\mathrm{NO}_{2}+\mathrm{CO}_{2} \\ \text { 1a. } & \mathrm{BaO}-\mathrm{CO}_{2} & \stackrel{k_{1 a}^{B a}}{\longrightarrow} & \mathrm{BaO}+\mathrm{CO}_{2} \\ \text { 1b. } & \mathrm{BaO}+\mathrm{NO}_{2} & \stackrel{k_{1 b}^{B a}}{\longrightarrow} & \mathrm{BaO}-\mathrm{NO}_{2} \\ \text { 2. } & \mathrm{BaO}-\mathrm{NO}_{2}+\mathrm{NO} & \stackrel{k_{2}^{B a}}{\longrightarrow} & \mathrm{Ba}\left(\mathrm{NO}_{2}\right)_{2} \\ \text { 2a. } & \mathrm{BaO}-\mathrm{NO}_{2}+\mathrm{NO}_{2} & \stackrel{k_{2 a}^{B a}}{\longrightarrow} & \mathrm{Ba}\left(\mathrm{NO}_{2}\right)\left(\mathrm{NO}_{3}\right)\end{array}$

accurate description of the measured effects of $\chi(0)$ on NO oxidation rates than sequential pathways (eq 27 and steps 1a and $1 \mathrm{~b}$ of Scheme 2). These conclusions are consistent with DFT estimates of $\mathrm{NO}_{2}$ binding energies on model $\mathrm{BaCO}_{3}$ slabs, which suggest that the formation of vacancies by $\mathrm{CO}_{2}$ desorption is unfavorable. ${ }^{39}$ Our results indicate that such pathways are also kinetically inaccessible and that $\mathrm{NO}_{2}$ chemisorption occurs via concerted displacement of chemisorbed $\mathrm{CO}_{2}$ with $\mathrm{NO}_{2}$.

The displacement of chemisorbed $\mathrm{CO}_{2}$ by $\mathrm{NO}_{2}$ (Scheme 2, step 1) may be followed, however, by other adsorption events. For example, we have observed that the cumulative amount of $\mathrm{NO}$ and $\mathrm{NO}_{2}$ retained by the adsorbent is about two times larger $(2.0 \pm 0.4)$ than the cumulative amount of $\mathrm{CO}_{2}$ eluted over the same time period. These data suggest that a second $\mathrm{NO}$ or $\mathrm{NO}_{2}$ molecule immediately adsorbs after the first adsorption event to form a nitrite, $\mathrm{Ba}\left(\mathrm{NO}_{2}\right)_{2}$ (step 2, Scheme 2) or a nitrite-nitrate pair, $\mathrm{Ba}\left(\mathrm{NO}_{2}\right)\left(\mathrm{NO}_{3}\right)$ (step $2 \mathrm{a}$, Scheme 2). If $\mathrm{NO}_{2}$ is the second molecule adsorbed, our treatment above remains unchanged, except our estimate of the number of $\mathrm{NO}_{2}$ binding sites would decrease by half since each binding sites adsorbs two $\mathrm{NO}_{x}$ species. Thus, we consider only the implications of a second adsorption event that involves NO, because such events would lead to NO oxidation rates no longer given solely by the depletion on NO from the effluent stream, because NO would also be consumed via adsorption onto sites already containing chemisorbed $\mathrm{NO}_{2}$.

DFT studies showed that the adsorption of a second NO or $\mathrm{NO}_{2}$ species onto a $\mathrm{BaO}$ site stabilizes isolated chemisorbed $\mathrm{NO}_{x}$ species. ${ }^{40-42}$ Low exposures of $\mathrm{NO}_{2}\left(<10^{-4} \mathrm{~Pa}-\mathrm{s}\right)$ to $\mathrm{BaO}$ surfaces formed nitrite and nitrate species at $100 \mathrm{~K}$, but only nitrites at $300 \mathrm{~K}$, consistent with molecular adsorption of two $\mathrm{NO}_{2}$ species onto a single $\mathrm{BaO}$ site at the lower temperatures (step $2 \mathrm{a}$ of Scheme 2). ${ }^{43,44} \mathrm{We}$ have observed that $\mathrm{NO}$ and $\mathrm{NO}_{2}$ were consumed in equimolar amounts upon exposure of $\mathrm{BaCO}_{3} /$ $\mathrm{Al}_{2} \mathrm{O}_{3}$ to $\mathrm{NO} / \mathrm{NO}_{2}$ mixtures (170 Pa NO, $\left.30 \mathrm{~Pa} \mathrm{NO}{ }_{2}, 573 \mathrm{~K}\right),{ }^{45}$ consistent with the exclusive formation of nitrites via concurrent adsorption of $\mathrm{NO}$ and $\mathrm{NO}_{2}$ (Scheme 2, step 2), instead of the adsorption of two $\mathrm{NO}_{2}$ molecules, even at the $\mathrm{NO} / \mathrm{NO}_{2}$ ratios $(\sim 6)$ and high temperatures in these experiments. The additional NO adsorption step (Scheme 2, step 2) occurs at the same rate as the first adsorption step (step 1 of Scheme 2) so that $\mathrm{BaO}-$ $\mathrm{NO}_{2}$ species remain at pseudosteady state and $\mathrm{NO}_{2} / \mathrm{NO}$ consumption ratios at their measured equimolar values. The NO conversion rate, $r_{N \mathrm{O}}$, in the catalyst-adsorbent mixtures is then given by:

$$
r_{\mathrm{NO}}=k_{\mathrm{Pt}} \frac{[\mathrm{NO}]\left[\mathrm{O}_{2}\right]}{\left[\mathrm{NO}_{2}\right]}+\frac{k_{1}^{\mathrm{Ba}}\left[\mathrm{NO}_{2}\right]}{\chi(0)}
$$

where the first term describes NO oxidation on Pt sites and the second term describes $\mathrm{NO}$ adsorption on $\mathrm{BaO}-\mathrm{NO}_{2}$. The expression for the $\mathrm{NO}_{2}$ concentration (eq 24) remains unchanged and its insertion into eq 28 yields NO oxidation rates given by

$$
r_{N O}=2\left(\frac{k_{P t} k_{1}^{B a}[N O]\left[O_{2}\right]}{\chi(0)}\right)^{1 / 2}
$$

We conclude that NO conversion rates on catalyst-adsorbent mixtures depend similarly on the catalyst/adsorbent ratio, $\chi(0)$, for $\mathrm{NO}_{2}$ and $\mathrm{NO}$ adsorption events that occur concurrently (eq 29) and for the direct adsorption of a single $\mathrm{NO}_{2}$ (eq 26). 
Synergistic effects of $\mathrm{NO}_{2}$ adsorption and $\mathrm{NO}$ oxidation sites present within typical diffusion distances for $\mathrm{NO}_{2}(\mathrm{~g})$ reflect the local depletion of $\mathrm{NO}_{2}$ molecules, which inhibit $\mathrm{NO}$ oxidation even at undetectable pressures $(<1 \mathrm{~Pa}) . \mathrm{NO}_{2}$ inhibits rates at the low $\mathrm{O}_{2}$ virtual pressures and chemical potentials $\left(10^{-6}-10^{-5}\right.$ $\mathrm{kPa}$ ) prevalent in intrapellet mixtures, because $\mathrm{O}^{*}$ remains present at near- saturation coverages, as a result of its strong binding energy $\left(Q_{\mathrm{o}} \sim 270 \mathrm{~kJ}\left(\mathrm{~mol} \mathrm{O}_{2}\right)^{-1}\right){ }^{23}$ Proximity among adsorption and catalytic sites influences these synergistic effects because intimacy (in the $\sim 1 \mu \mathrm{m}$ length scale) prevents intrapellet $\mathrm{NO}_{2}$ concentration gradients, but atomic connectivity between $\mathrm{BaO}$ and $\mathrm{Pt}$ sites does not appear to be required for the depletion of $\mathrm{NO}_{2}$ near Pt surfaces.

\section{Conclusions}

The kinetics of NO oxidation on Pt clusters are consistent with a mechanism involving kinetically relevant $\mathrm{O}_{2}$ reaction with vacancies in chemisorbed oxygen monolayers. Chemisorbed $\mathrm{O}^{*}$ coverages during NO oxidation are characterized by an oxygen virtual pressure, which is determined by the thermodynamics of $\mathrm{NO}-\mathrm{NO}_{2}$ interconversion reactions. The virtual pressure concept shows that NO oxidation rates depend on the dynamics of $\mathrm{O}_{2}$ interactions with vacancies and on the thermodynamics of $\mathrm{O}^{*}$ binding, and also allows $\mathrm{NO}$ oxidation to be rigorously compared with oxygen isotopic exchange. Both processes have similar rate constant parameters, consistent with the kineticrelevance of $\mathrm{O}_{2}$ reaction with a vacancy to form $\mathrm{O}^{*}$ and a mobile oxygen intermediate. Apparent activation energies for both forward and reverse $\mathrm{NO}$ oxidation rates and isotopic exchange reflect primarily heats of $\mathrm{O}^{*}$ adsorption; rates of all of these reactions are much higher on large clusters, which bind oxygen more weakly than small clusters. These trends with cluster size, which are observed for $\mathrm{CH}_{4}$ and dimethyl ether oxidation, but not for $\mathrm{CO}$ oxidation, are general for reactions occurring on O* covered surfaces. Bulk oxidation did not contribute to the cluster size effects measured here because the NO oxidation rate constant for small clusters was constant and uniformly lower than that for large, metallic clusters over a wide range of oxygen virtual pressures, suggesting that every cluster had identical phase throughout the measurement.

$\mathrm{NO}_{2}$ adsorption sites present within diffusion distances of catalyst sites increase $\mathrm{NO}$ oxidation rates by scavenging $\mathrm{NO}_{2}$ molecules that inhibit NO oxidation even at the low pressures $(<1 \mathrm{~Pa})$ in catalyst-adsorbent systems. A simple reactionadsorption model in which $\mathrm{NO}_{2}$ adsorbs via displacement of $\mathrm{CO}_{2}$ on $\mathrm{BaCO}_{3}$ surfaces accurately describes $\mathrm{NO}$ oxidation rates on intrapellet catalyst-adsorbent mixtures. The persistent $\mathrm{NO}_{2}$ inhibition of $\mathrm{NO}$ oxidation catalysis implies that the dynamics of $\mathrm{NO}_{2}$ adsorption control $\mathrm{NO}$ oxidation rates and noble metal efficiency in $\mathrm{NO}_{x}$ storage systems.

Acknowledgment. We thank the Ford Motor Company for financial support and Drs. Robert McCabe and George W. Graham for technical advice. B.W. acknowledges the support from Chevron in the form of the Berkeley-Chevron Graduate Fellowship. We also thank Dr. Jon G. McCarty (Eaton Corp.) for technical advice about the $\mathrm{Pt}-\mathrm{PtO}_{x}$ phase behavior, and Prof. Matthew Neurock (University of Virginia) for discussions about electronic effects in catalysis.

Supporting Information Available: A.1 Rates of ${ }^{16} \mathrm{O}_{2}-{ }^{18} \mathrm{O}_{2}$ and ${ }^{18} \mathrm{O}_{2}-{ }^{16} \mathrm{O}^{*}$ exchange on $\mathrm{Pt} / \mathrm{Al}_{2} \mathrm{O}_{3}$; A.2 Calculation of the Mears parameter in catalyst-adsorbent mixtures. This material is available free of charge via the Internet at http://pubs.acs.org.

\section{References and Notes}

(1) Takahashi, N.; Shinjoh, H.; Iijima, T.; Suzuki, T.; Yamazaki, K.; Yokota, K.; Suzuki, H.; Miyoshi, N.; Matsumoto, S.; Tanizawa, T.; Tanaka, T.; Tateishi, S.; Kasahara, K. Catal. Today 1996, 27, 63.

(2) Epling, W. S.; Campbell, L. E.; Yezerets, A.; Currier, N. W.; Parks, J. E. Catal. Rev. Sci. Eng. 2004, 46, 163.

(3) Gandhi, H. S.; Graham, G. W.; McCabe, R. W. J. Catal. 2003, 216,433 .

(4) Mulla, S. S.; Chen, N.; Delgass, W. N.; Epling, W. S.; Ribeiro, F. H. Catal. Lett. 2005, 100, 267.

(5) Getman, R. B.; Xu, Y.; Schneider, W. F. J. Phys. Chem. C 2008, 112,9559 .

(6) Mulla, S. S.; Chen, N.; Cumaranatunge, L.; Blau, G. E.; Zemlyanov, D. Y.; Delgass, W. N.; Epling, W. S.; Ribeiro, F. H. J. Catal. 2006, 241, 389.

(7) Kwak, J. H.; Kim, D. H.; Szailer, T.; Peden, C. H. F.; Szanyi, J. Catal. Lett. 2006, 111, 119.

(8) Cant, N. W.; Liu, I. O. Y.; Patterson, M. J. J. Catal. 2006, 243, 309.

(9) Nova, I.; Castoldi, L.; Lietti, L.; Tronconi, E.; Forzatti, P.; Prinetto, F.; Ghiotti, G. J. Catal. 2004, 222, 377.

(10) Briot, P.; Auroux, A.; Jones, D.; Primet, M. Appl. Catal. 1990, 59, 141.

(11) Fujimoto, K.; Ribeiro, F. H.; Avalos-Borja, M.; Iglesia, E. J. Catal. 1998, $179,431$.

(12) Ishikawa, A.; Neurock, M.; Iglesia, E. J. Am. Chem. Soc. 2007, 129, 13201.

(13) Epling, W. S.; Peden, C. H. F.; Szanyi, J. J. Phys. Chem. C 2008, 112, 10952.

(14) David, R. L. Handbook of Chemistry and Physics, 87th ed.; CRC Press: Boca Raton, FL, 2006.

(15) Smeltz, A. D.; Getman, R. B.; Schneider, W. F.; Ribeiro, F. H. Catal. Today 2008, 136, 84.

(16) Koros, R. M.; Nowak, E. J. Chem. Eng. Sci. 1967, 22, 470.

(17) Biscardi, J. A.; Iglesia, E. J. Phys. Chem. B 1998, 102 (46), 9284.

(18) Boreskov, G. K. Adv. Catal. 1964, 15, 285.

(19) Holstein, W. L.; Boudart, M. J. Phys. Chem. B 1997, 101, 9991.

(20) Boreskov, G. K. Faraday Discuss. 1966, 41, 263.

(21) Amirnazmi, A.; Benson, J. E.; Boudart, M. J. Catal. 1973, 30, 55.

(22) Voltz, S. E.; Morgan, C. R.; Liederman, D.; Jacob, S. M. Ind. Eng. Chem. Prod. Res. Develop. 1973, 12, 294.

(23) Sen, B.; Vannice, M. A. J. Catal. 1991, 129, 31.

(24) Han, B. C.; Miranda, C. R.; Ceder, G. Phys. Rev. B 2008, 77, 075410.

(25) Yeo, Y. Y.; Vattuone, L.; King, D. A. J. Chem. Phys. 1997, 106, 392.

(26) Wartnaby, C. E.; Stuck, A.; Yeo, Y. Y.; King, D. A. J. Phys. Chem. 1996, 100,12483 .

(27) Shan, B.; Kapur, N.; Hyun, J.; Wang, L.; Nicholas, J. B.; Cho, K.

J. Phys. Chem. C 2009, 113, 710 .

(28) Ladas, S.; Poppa, H.; Boudart, M. Surf. Sci. 1981, 1, 151.

(29) McCarthy, E.; Zahradnik, J.; Kuczynski, G. C.; Carberry, J. J. J. Catal. 1975, 39, 29.

(30) Ogletree, D. F.; Van Hove, M. A.; Somorjai, G. A. Sur. Sci. 1986, 173,351

(31) Brewer, L. Chem. Rev. 1953, 52, 1.

(32) Samsonov, G. V. The Oxide Handbook, 2nd ed.; Plenum: New York, 1982.

(33) Muller, O.; Roy, R. J. Less Common Met. 1968, 16, 129.

(34) Wang, C.-B.; Yeh, C.-T. J. Catal. 1998, 178, 450.

(35) Campbell, C. T.; Parker, S. C.; Starr, D. E. Science 2002, 298, 811.

(36) Grass, M. E.; Zhang, Y. W.; Butcher, D. R.; Park, J. Y.; Li, Y. M.; Bluhm, H.; Bratlie, K. M.; Zhang, T. F.; Somorjai, G. A. Angew. Chem., Int. Ed. 2008, 47, 8893.

(37) Yung, M. M.; Holmgreen, E. M.; Ozkan, U. S. J. Catal. 2007, 247, 356.

(38) Mears, D. E. Ind. Eng. Chem. Process Des. Dev. 1971, 10, 541. (39) Broqvist, P.; Panas, I.; Gronbeck, H. J. Phys. Chem. B 2005, 109, 9613

(40) Schneider, W. F.; Hass, K. C.; Miletic, M.; Gland, J. L. J. Phys. Chem. B 2002, 106, 7405 .

(41) Schneider, W. F. J. Phys. Chem. B 2004, 108, 273.

(42) Broqvist, P.; Panas, I.; Fridell, E.; Persson, H. J. Phys. Chem. B 2002, 106, 137.

(43) Desikusumastuti, A.; Staudt, T.; Happel, M.; Laurin, M.; Libuda, J. J. Catal. 2008, 260, 315.

(44) Yi, C.-W.; Kwak, J. H.; Szanyi, J. J. Phys. Chem. C 2007, 111, 15299.

(45) Weiss, B. M.; Iglesia, E. Unpublished results.

JP902209F 